\title{
Prefrontal Cortex to Accumbens Projections in Sleep Regulation of Reward
}

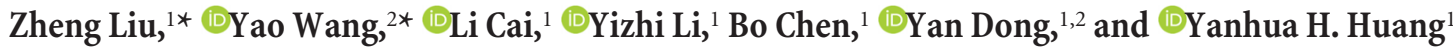 \\ Departments of ${ }^{1}$ Psychiatry and ${ }^{2}$ Neuroscience, University of Pittsburgh, Pittsburgh, Pennsylvania 15219
}

Sleep profoundly affects the emotional and motivational state. In humans and animals, loss of sleep often results in enhanced motivation for reward, which has direct implications for health risks as well as potential benefits. Current study aims at understanding the mechanisms underlying sleep deprivation (SDe)-induced enhancement of reward seeking. We found that after acute SDe, mice had an increase in sucrose seeking and consumption but not food intake, suggesting a selective enhancement of motivation for reward. In the nucleus accumbens (NAc), a key brain region regulating emotional and motivational responses, we observed a decrease in the ratio of the overall excitatory over inhibitory synaptic inputs onto NAc principle neurons after SDe. The shift was partly mediated by reduced glutamatergic transmission of presynaptic origin. Further analysis revealed that there was selective reduction of the glutamate release probability at the medial prefrontal cortex (mPFC)-to-NAc synapses, but not those from the hippocampus, thalamus, or the basal lateral amygdala. To reverse this SDe-induced synaptic alteration, we expressed the stabilized step function opsin (SSFO) in the mPFC; optogenetic stimulation of SSFO at mPFC-to-NAc projection terminals persistently enhanced the action potential-dependent glutamate release. Intra-NAc optogenetic stimulation of SSFO selectively at mPFC-to-NAc terminals restored normal sucrose seeking in mice after SDe without affecting food intake. These results highlight the mPFC-to-NAc projection as a key circuit-based target for sleep to regulate rewardmotivated behaviors.

Key words: accumbens; mPFC; reward; self-administration; sleep; SSFO

\section{Significance Statement}

Sleep loss, a costly challenge of modern society, has profound physiological and psychological consequences, including altered reward processing of the brain. The current study aims at understanding the mechanisms underlying sleep deprivation-induced enhancement of reward seeking. We identify that the medial prefrontal cortex (mPFC)-to-nucleus accumbens (NAc) glutamatergic transmission is selectively weakened following acute sleep deprivation, whose restoration normalizes reward seeking in sleep-deprived mice. These results suggest a possibility of normalizing sleep deprivation-induced abnormal reward seeking by targeting specific neural projections, and they demonstrate the mPFC-to-NAc glutamatergic projection as a key circuit-based target for sleep to regulate reward-motivated behaviors.

\section{Introduction}

Seeking reward drives the lives of animals forward, while abnormally enhanced or compromised reward processing is implicated

Received Jan. 31, 2016; revised May 17, 2016; accepted June 6, 2016.

Author contributions: Z.L., Y.W., L.C., Y.L., B.C., Y.D., and Y.H.H. designed research; Z.L., Y.W., L.C., Y.L., and B.C. performed research; Z.L., Y.W., L.C., Y.L., B.C., and Y.H.H. analyzed data; Z.L., Y.W., L.C., Y.D., and Y.H.H. wrote the paper.

This work was supported by NIH Grant MH101147 (Y.H.H.), DA035805 (Y.H.H.), DA029565 (Y.H.H.), DA023206 (Y.D.), and DA034856 (Y.D.) and the Pennsylvania Department of Health (Y.H.H.). We thank Yao-Ying Ma and Mary Torregrossa for programming support with the self-administration apparatus, Shawn Singh and Jackson Mitzner for assistance with sleep deprivation studies, Ryan Smyth and Alisa Kim for assistance with genotyping, and Susan Sesack for helpful discussions on the excitatory inputs to the accumbens.

*Z.L. and Y.W. contributed equally to this work.

The authors declare no competing financial interests.

Correspondence should be addressed to Dr. Yanhua H. Huang, Department of Psychiatry, University of Pittsburgh, 450 Technology Drive, Pittsburgh, PA 15219. E-mail: yhhuang@pitt.edu. in several detrimental psychiatric illnesses. In both humans and experimental animals, sleep is a prominent factor regulating reward processing of the brain. Following acute sleep deprivation (SDe), amplified positive emotion and enhanced motivation for reward have been consistently observed across multiple modalities, including high-calorie food wanting, monetary reward seeking and risk taking, drug and alcohol intake, and intracranial self-stimulations (Steiner and Ellman, 1972; Brower et al., 1998; Killgore et al., 2006; McKenna et al., 2007; Venkatraman et al., 2007, 2011; Puhl et al., 2009, 2013; Gujar et al., 2011; Greer et al., 2013; Telzer et al., 2013). On the bright side, SDe has been used as a fast-acting alternative treatment for the broadly defined depressive syndrome (Giedke and Schwärzler, 2002; Hemmeter 
et al., 2010; Dallaspezia and Benedetti, 2015). However, the neural circuit mechanisms underlying sleep regulation of reward remain elusive.

The nucleus accumbens (NAc) is considered a limbic-motor interface that integrates reward and motivational inputs and translates them for motor outputs (Mogenson et al., 1980; Robbins and Everitt, 1996; Kelley, 2004). Excitatory glutamatergic inputs carrying information of context, cues, and behavioral control from the prefrontal cortex (PFC), hippocampus, basolateral amygdala (BLA), thalamus, and other regions converge onto the NAc (Phillipson and Griffiths, 1985; Sesack and Grace, 2010; Salgado and Kaplitt, 2015). Alterations in glutamatergic transmission or the balance between excitatory and inhibitory inputs $(\mathrm{E} / \mathrm{I})$ to the NAc lead to a variety of types of reward malfunctioning, including overeating and drug abuse (Kalivas and Volkow, 2005; Baldo and Kelley, 2007). Whereas the glutamatergic inputs come from brain regions that are dynamically responsive to sleep (Muzur et al., 2002; Marshall and Born, 2007; Yoo et al., 2007; David et al., 2013), it is not known whether and how their synaptic contacts on NAc neurons are affected by sleep or sleep loss. The present study aims to characterize whether and how SDe affects the glutamatergic projections to NAc neurons and the overall E/I balance and determine how these SDe-induced alterations may affect reward-elicited behaviors.

Our results show that acute SDe enhanced sucrose selfadministration in mice. As a neural correlate, we found a shift in the E/I balance within the NAc toward lower excitatory drive onto NAc principal neurons following SDe. This shift was, at least partially, mediated by reduced glutamate release from presynaptic terminals. Further evidence suggests that the release probability (Pr) of medial PFC (mPFC)-to-NAc synapses, but not synapses from the hippocampal, thalamic, or BLA projections, was reduced. Moreover, reversing this projection-specific synaptic alteration by optogenetically boosting the Pr at mPFC-to-NAc synapses rescued SDe-induced abnormal reward seeking. These results provide a circuit-based understanding about sleepmediated regulation of reward seeking.

\section{Materials and Methods}

\section{Subjects}

Male C57BL/6 mice (Harlan) or Drd1a-tdTomato mice (Jackson Laboratory, stock \#016204), 6-8 weeks old, were used at the beginning of the experiments. Mice were maintained at room temperature $\left(22 \pm 1^{\circ} \mathrm{C}\right)$ and controlled humidity $(60 \pm 5 \%)$ under a $12 \mathrm{~h}$ light/dark cycle (lights on at 7:00 A.M., off at 7:00 P.M.), and housed individually with constant access to food and water. Mouse usage was in accordance with protocols approved by the Institutional Animal Care and Use Committee at the University of Pittsburgh.

\section{Sleep deprivation}

Mice were subjected to SDe through the gentle-handling method, which consists of keeping the animals awake in their home cages by introducing fresh bedding and nesting material, gently tapping on or moving the cage, and, if necessary, gently touching the tail with a soft brush whenever behavioral signs of sleep, such as closed eyes or sleep posture, are observed (Cirelli and Tononi, 2004; Colavito et al., 2013). Mice were sleep deprived for 6 h (7:00 A.M.-1:00 P.M.). Mice had food and water ad libitum throughout the entire procedure.

\section{Behavioral scoring}

Two groups of mice ( $n=8$ each group) were manually scored for behavioral states between 7:00 A.M. and 1:00 P.M. under control conditions or SDe using criteria as follows: exploring (moving around in the cage, working on bedding and nesting material, hanging), feeding (working on food or water), quiet time (including being quietly awake, sitting with eyes open or with fine movement; and sleeping, eyes closed or sleep posture). As it is difficult to behaviorally determine the actual sleep state, sleep time was determined by EEG/EMG recordings in separate groups of mice (see the following section).

\section{EEG surgery, recording, and analysis}

A group of six mice was used for EEG/EMG recordings. The surgery to install the EEG apparatus was similar to that described previously (Krueger and Obal, 1993; Winters et al., 2011; Chen et al., 2015). Briefly, two stainless-steel wire EMG electrodes were inserted into the nuchal neck muscle, and two gold-plated wire EEG electrodes (Plastics One) were installed contralaterally through the skull over the parietal and frontal cortices. Electrode leads were gathered into a plastic socket (Plastics One) and fixed to the skull with dental cement. All mice were singly housed after surgery and during subsequent experiments.

EEG and EMG electrodes were connected to the amplifiers via lightweight cables and commutators (Plastics One). Mice were allowed to habituate for 3-6 d before data collection. Baseline EEG and EMG signals were typically recorded around postnatal day 50 and recorded for 2-3 d before SDe. EEG and EMG signals were amplified using Grass model 15LT bipolar amplifiers (Grass Technologies) and an analog-to-digital converter (Contec, USA). The EEG was filtered below $0.1 \mathrm{~Hz}$ and above $100 \mathrm{~Hz}$. The EMG was filtered below $30 \mathrm{~Hz}$ and above $3 \mathrm{kHz}$. All signals were digitized at $128 \mathrm{~Hz}$ and collected using Vital Recorder software (Kissei Comtec). All signals were manually scored for sleep states in $10 \mathrm{~s}$ epochs using Sleep Sign for Animal software (Kissei Comtec). Wakefulness was identified by desynchronized EEG and high EMG activities; non-rapid eye movement (NREM) sleep exhibited high-amplitude slow waves and lower EMG activity; and rapid eye movement (REM) sleep exhibited typical EEG theta activity and extremely low EMG activity. Consolidated sleep durations were determined by the same sleep states in a stretch of time of no less than $20 \mathrm{~s}$ (two epochs). For the EEG power spectrum analysis, EEG signals underwent fast Fourier transformation using a $0.5 \mathrm{~Hz}$ frequency bin and were normalized to the average delta power $(0-4 \mathrm{~Hz}$ for NREM) or theta power $(5-10 \mathrm{~Hz}$ for REM) of the baseline condition (before SDe). All data were coded for sleep scoring and then decoded for data compiling. SDe and recovery sleep were compared with the sleep on baseline days.

\section{Plasma corticosterone assay}

Three groups of mice ( $n=8$ each group) singly housed in the same conditions were used for this assay. One group was sleep deprived by the method described above. Another group was allowed to have normal sleep in their home cages during the same period and served as negative controls. Both groups had $20 \mathrm{~min}$ of wakeful time after 1:00 P.M. before blood sampling. A third group was subjected to acute physical restraint for $30 \mathrm{~min}$ in mouse restrainers before blood sampling and served as positive stress controls. All blood samples were collected at the same time of the day, at $\sim 1: 30-2: 00$ P.M.

The mice were decapitated after isoflurane anesthesia, and trunk blood was collected in heparin-containing tubes. Samples were kept on ice for $<30 \mathrm{~min}$ before being centrifuged at $1500 \times \mathrm{g}$ at $4^{\circ} \mathrm{C}$ for $10 \mathrm{~min}$. The supernatant was stored at $-80^{\circ} \mathrm{C}$ for later analysis. Plasma corticosterone concentrations were determined by Corticosterone ELISA Kit (Enzo Life Sciences).

\section{Sucrose self-administration}

Sucrose self-administration training was conducted in operantconditioning chambers (Med Associates), each containing an active and an inactive lever, a conditioned stimulus (CS) light above each lever, a house light, and a food dispenser. Pressing the active lever resulted in the delivery of a sucrose pellet (20 mg; Bio-Serv, catalog \#F05301, chocolate flavored) and illumination of a CS light above the active lever for $1 \mathrm{~s}$. Pressing the inactive lever had no reinforcement consequences. Mice were trained overnight on the first night on a fixed ratio (FR) 1 reinforcement schedule, followed by FR3 on the third night and FR5 on the fifth night. The mice were then trained on the FR5 schedule for $30 \mathrm{~min}$ daily until a stable baseline across 3 or $4 \mathrm{~d}$ was obtained. On baseline days, the mice were aroused for $\sim 20 \mathrm{~min}$ before tests. The baseline level was determined by the $3 \mathrm{~d}$ average before SDe. On SDe days, the mice underwent SDe from 7:00 A.M. to 1:00 P.M. and were tested thereafter. The 
A

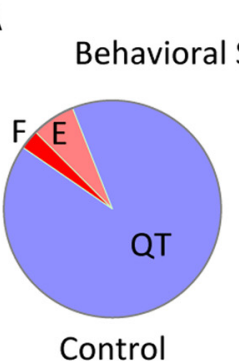

B

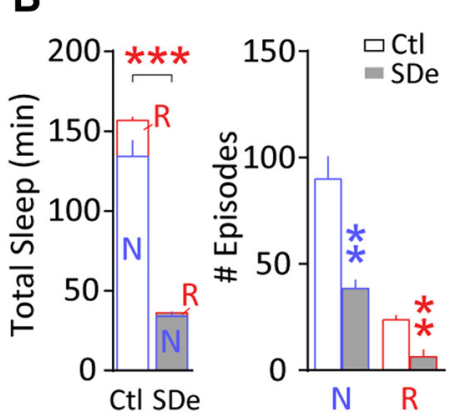

C

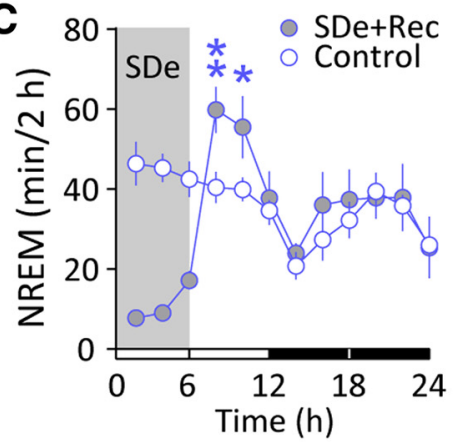

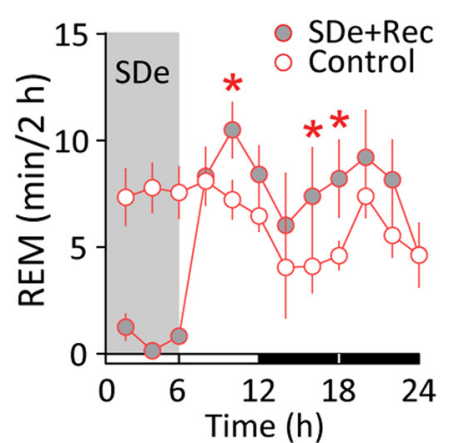

E

Time $(\mathrm{h})$

D NREM $\quad \therefore$ Rec
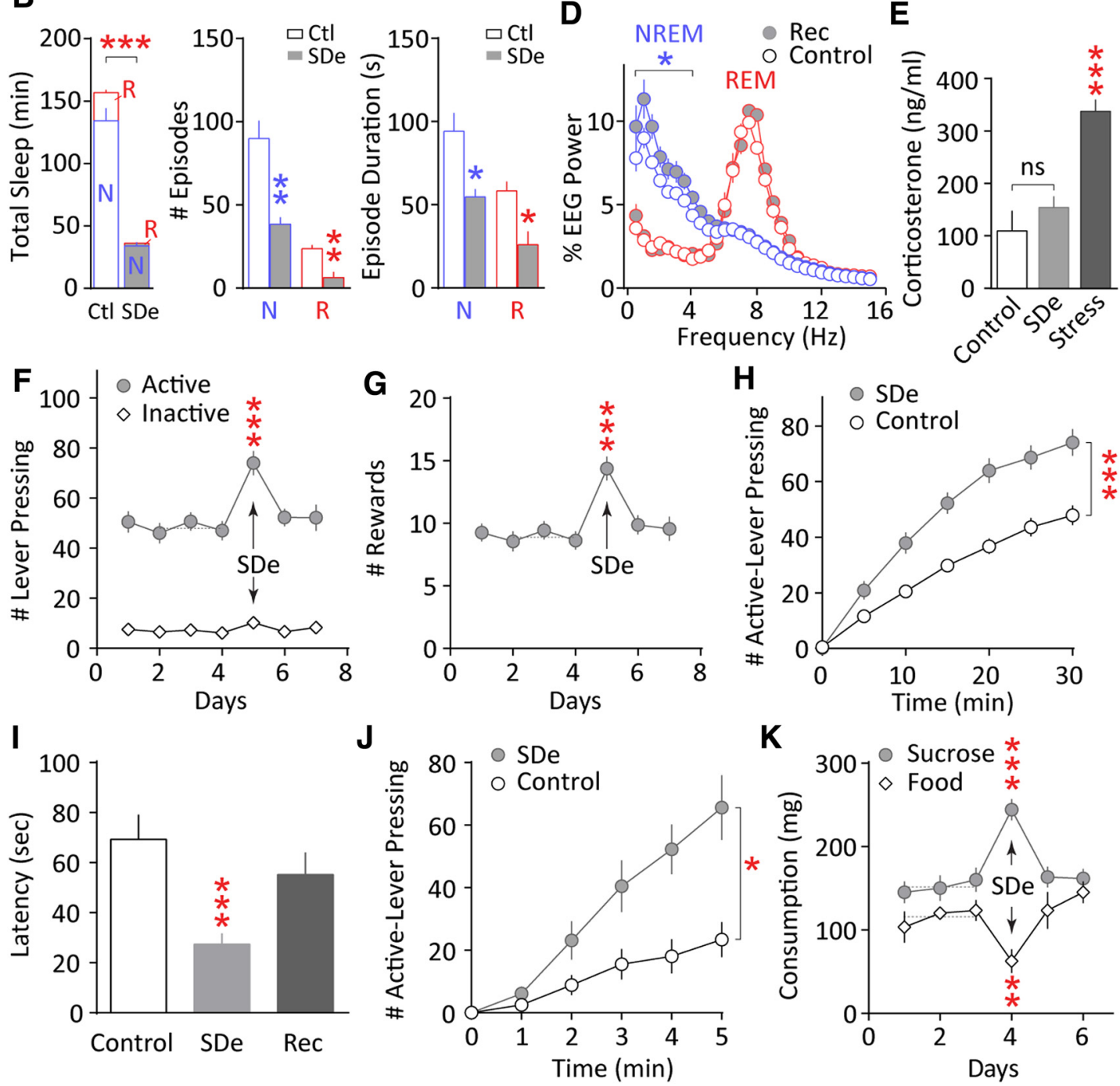

Figure 1. SDe enhances motivation for sucrose reward. A, Mouse behavioral states were manually scored under control conditions or SDe between 7:00 A.M. and 1:00 P.M. Compared to the control group, mice under SDe spent less quiet time and increased the time exploring and feeding. $n=8$ each group. $B$, Sleep measurements based on EEG and EMG signals showing that, compared to the baseline control days, SDe decreased total sleep time (left), resulting from fewer numbers of NREM and REM sleep episodes (middle) and shorter durations of the individual sleep episodes (right). $n=6$. C, NREM and REM sleep time calculated in $2 \mathrm{~h}$ bins showing reduction during SDe and rebound during recovery sleep. $n=6 . D$, NREM and REM power spectra during the first hour of recovery sleep, showing rebound delta power in the $0.5-4.0 \mathrm{~Hz}$ range during NREM sleep. $n=6 . E$, Plasma corticosterone levels measured following control conditions, SDe, or acute physical restraint stress (Stress) showing no significant increase upon SDe and a significantincrease upon acutestress. $n=7-8$ each group. $F$, Micetrained to self-administer sucrosepellets were able to maintain a stable level oflever pressing over multipledays under an FR5 schedule. Lever pressing at the active lever was increased following SDe and normalized $1 \mathrm{~d}$ after SDe. The number of inactive-lever presses remained low throughout the course. $n=16$. Asterisks indicate significance compared to the average of the $3 \mathrm{~d}$ baseline beforeSDe. G, The number of sucrose pellets obtained by lever pressing showed a similar increase following SDe, which recovered after $1 \mathrm{~d} . n=16$. Asterisks indicate significance compared to the average of the $3 \mathrm{~d}$ baseline before SDe. $\boldsymbol{H}$, Cumulative plot of active-lever pressing for the 30 min test in 5 min bins. $n=16$. Asterisks indicate the main effect of SDe; $p<0.01$ or less at each time point from 5 to $30 \mathrm{~min}$. I, The latency, defined as the time elapsed before first press of the active lever, was decreased following SDe and recovered $1 \mathrm{~d}$ after SDe. $n=16$. Asterisks indicate significance compared to the average of the $3 \mathrm{~d}$ baseline before SDe.J, Lever pressing without delivery of sucrose pellets was recorded for a 5 min test. The number of presses of the active lever was increased following SDe. $n=10$. Asterisks indicate the main effect of SDe. $\boldsymbol{K}$, In two separate tests, the free consumption of either sucrose or food pellets was measured during 30 min tests on baseline days, following SDe, and after recovery sleep. Sucrose pellet consumption was increased following SDe, whereas food pellet consumption was decreased. Both effects returned to the baseline levels $1 \mathrm{~d}$ after recovery sleep. $n=12$ each group. Asterisks indicate significance compared to the average of the $3 \mathrm{~d}$ baseline before SDe. Dotted lines indicate the $3 \mathrm{~d}$ average before SDe as the baseline levels. All values are represented as mean \pm SEM. ${ }^{*} p<0.05 ;{ }^{* *} p<$ $0.01 ;{ }^{* * *} p<0.001$. QT, quiet time; E, exploring; F, feeding; Rec, recovery sleep; N, NREM; R, REM; Ctl, control. 
A

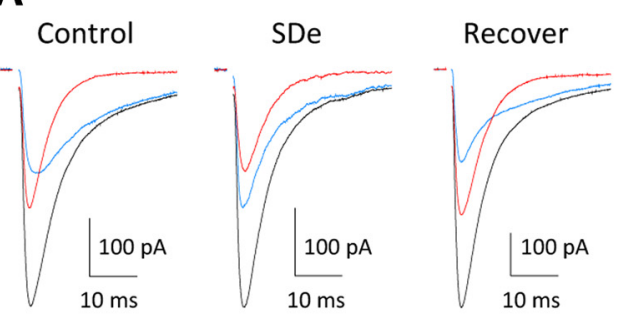

C

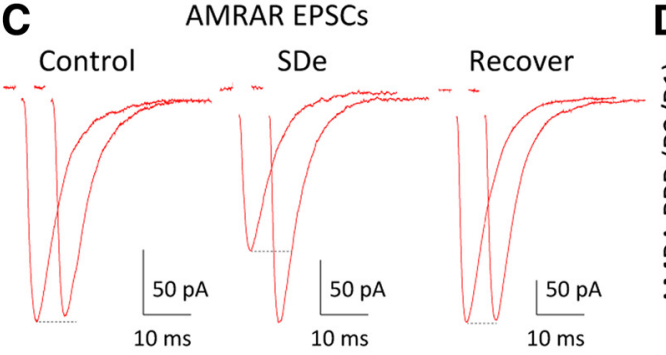

E

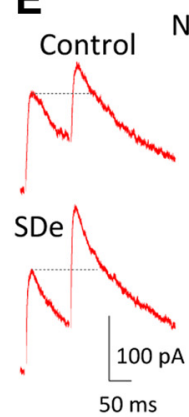

NMDAR EPSCS

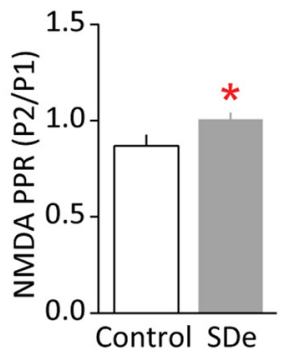

G

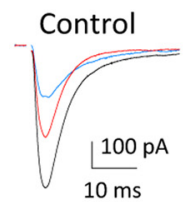

SDe

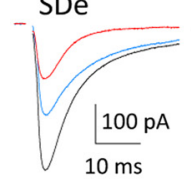

D1R MSN

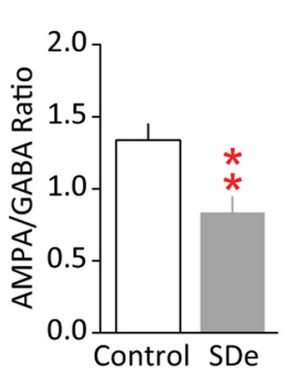

I

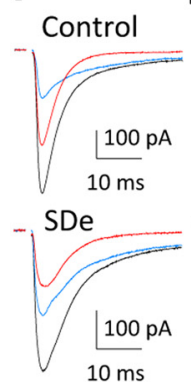

\section{D2R MSN}

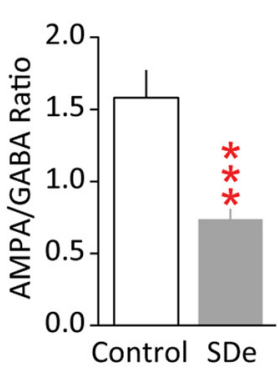

J
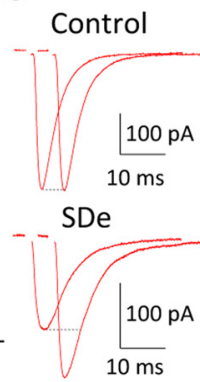

B
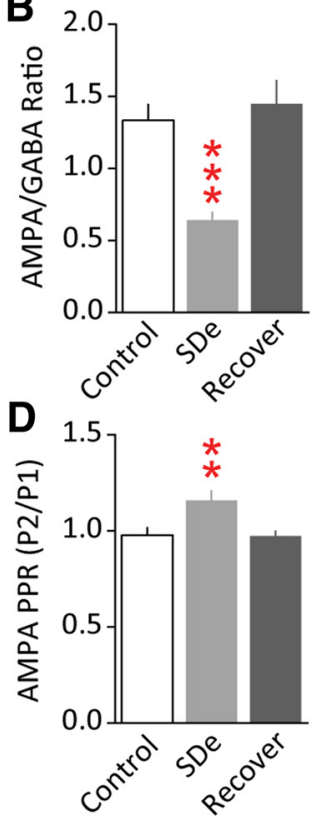

F Control

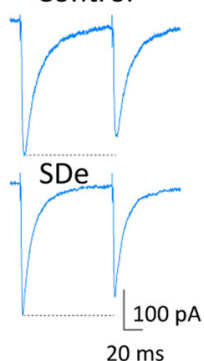

GABAAR IPSCS

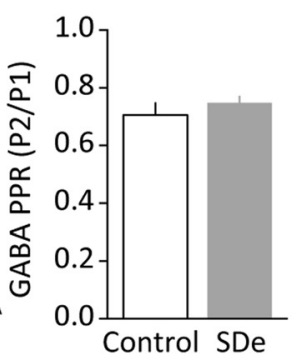

D1R MSN
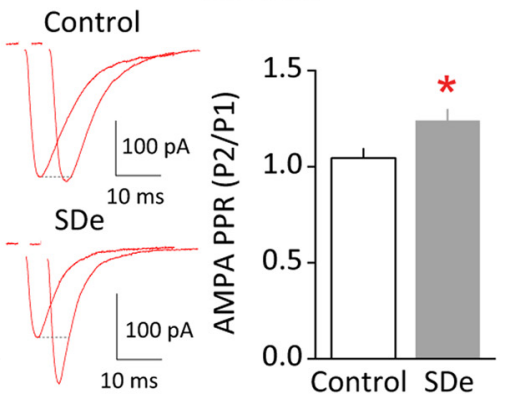

D2R MSN

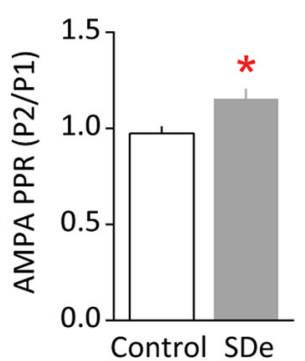

Figure 2. SDe reduces glutamatergic transmission onto NAc MSNs. A, Evoked mixed postsynaptic currents (black), AMPAR EPSCS (recorded in the presence of picrotoxin, $100 \mu \mathrm{m}$; red), and GABA ${ }_{A}$ IPSCS (subtracted; blue) in example NAc MSNs from mice after control sleep, SDe, or $1 \mathrm{~d}$ after SDe. $\boldsymbol{B}$, Summarized results showing that SDe significantly reduced the peak amplitude ratio of AMPA/GABA; the reduction was not detected in mice $1 \mathrm{~d}$ after SDe. $n=17-24$ cells per group from 8-11 mice each. C, Example AMPAR EPSCs evoked by paired-pulse stimulations (100 ms interpulse interval) in NAc MSNs from mice after control sleep, SDe, or

same mice were tested $1 \mathrm{~d}$ later, after recovery sleep. All daily trainings and tests occurred at $\sim$ 1:30 P.M. The mice had ad libitum access to water but not food during the overnight training. No water or food was provided for the 30 min daily trainings or tests.

Food or sucrose pellet consumption tests For the food consumption test, freely available, grain-based food pellets (20 mg; Bio-Serv, catalog \#F0163) were used under different sleep conditions. After adaptation to the food pellets and the testing chamber, all testing sessions occurred at $\sim 1: 30$ P.M. for 30 min daily. The mice were provided with a dish of food pellets at the beginning of the test, and the remaining pellets at the end of the $30 \mathrm{~min}$ test were counted to calculate the number of pellets consumed during the test. No water was provided during the test. Consumptions following normal sleep, SDe, and recovery sleep were compared. For the sucrose pellet consumption test, the mice underwent the same procedures except that that the sucrose pellets $(20 \mathrm{mg}$; BioServ, catalog \#F05301, chocolate flavored) were used instead of food pellets.

\section{Viral vectors}

Adeno-associated virus (AAV) vectors were used to express channelrhodopsin 2 (ChR2) or stabilized step function opsin (SSFO) with fluorescent markers in selected brain regions. AAV2-hSyn-ChR2-EYFP and AAV2-CaMK IIa-SSFO-mCherry were obtained from the University of North Carolina Vector Core.

$\leftarrow$

$1 \mathrm{~d}$ after SDe. D, Summarized results showing that the PPR of AMPAR EPSCS was increased after SDe and normalized $1 \mathrm{~d}$ after SDe. $n=16-21$ cells per group from $6-7$ mice each. $E$, Left, Example NMDAR EPSCs evoked by paired-pulse stimulations (100 ms interpulse interval) in NAc MSNs from mice after control sleep or SDe. Right, Summarized results showing increased PPR of NMDAR EPSCs after SDe. $n=15$ cells per group from 6-7 mice each. $\boldsymbol{F}$, Left, Example GABA ${ }_{A} R$ IPS(s evoked by paired-pulse stimulations (100 ms interpulse interval) in NAC MSNs from mice after control sleep or SDe. Right, Summarized results showing no change in IPSC PPR after SDe. $n=16$ cells per group from 6 mice each. $\boldsymbol{G}$, Left, Example postsynaptic currents (mixed, black; EPSC, red; IPSC, blue) in NAC D R MSNs from mice after control sleep or SDe. Right, Summarized results showing a decreased AMPA/GABA ratio after SDe. $n=$ 13-16 cells per group from 5-7 mice each. $\boldsymbol{H}$, Left, Example AMPAR EPSCs evoked by paired-pulse stimulations (100 ms interpulse interval) in NAC $D_{1} R$ MSNs from mice after control sleep or SDe. Right, Summarized results showing an increased PPR of AMPAR EPSCs after SDe (100 ms interpulse interval). $n=13-22$ cells per group from $5-8$ mice each. $I$, Left, Example postsynaptic currents (mixed, black; EPSC, red; IPSC, blue) in NAC $D_{2}$ R MSNs from mice after control sleep or SDe. Right, Summarized results showing a decreased AMPA/GABA ratio after SDe. $n=12-15$ cells per group from 5-7 mice each. $J$, Left, Example AMPAR EPSCs evoked by paired-pulse stimulations (100 ms interpulse interval) in NAC $D_{2}$ R MSNs from mice after control sleep or SDe. Right, Summarized results showing an increased PPR of AMPAR EPSCs after SDe ( $100 \mathrm{~ms}$ interpulse interval). $n=18-20$ cells per group from 5-7 mice each. ${ }^{*} p<0.05 ;{ }^{* *} p<0.01 ;{ }^{* * *} p<0.001$ (compared to mice without SDe). All values are represented as mean \pm SEM. 


\section{Stereotaxic surgeries}

For injection of viral vectors, mice were anesthetized with a ketamine/ xylazine mixture $(100 / 10 \mathrm{mg} / \mathrm{kg}$, i.p.) and placed in a stereotaxic apparatus (Kopf Instruments). A 34 gauge injection needle connected to a Hamilton syringe driven by a microinfusion pump (Harvard Apparatus) was used to bilaterally inject $1 \mu \mathrm{l}$ per site $(0.2 \mu \mathrm{l} / \mathrm{min})$ of the viral vector solution into one of the four targeted brain regions: the infralimbic mPFC ( $+1.75 \mathrm{~mm} \mathrm{AP,} \pm 0.45 \mathrm{~mm} \mathrm{ML},-2.8 \mathrm{~mm} \mathrm{DV})$, ventral hippocampus $(-2.9 \mathrm{~mm} \mathrm{AP}, \pm 2.8 \mathrm{~mm} \mathrm{ML},-4.4 \mathrm{~mm} \mathrm{DV})$, dorsal medial thalamus ( $-1.0 \mathrm{~mm} \mathrm{AP}, \pm 0.4 \mathrm{~mm} \mathrm{ML},-3.2 \mathrm{~mm} \mathrm{DV})$, and caudal BLA (cBLA; $-1.8 \mathrm{~mm} \mathrm{AP}, \pm 3.1 \mathrm{~mm} \mathrm{ML},-5.0 \mathrm{~mm} \mathrm{DV}$ ). These subregions are known to project to the medial dorsal NAc shell (Fig. 3), where we observed altered transmission following SDe (Fig. 2). For in vivo optogenetic studies, a guide cannula (26 gauge, stainless steel) was bilaterally implanted $1 \mathrm{~mm}$ above the NAc $(+1.55 \mathrm{~mm} \mathrm{AP}, \pm 0.6 \mathrm{~mm} \mathrm{ML},-3.4$ $\mathrm{mm} \mathrm{DV}$ ) and secured on the skull by a stainless-steel screw and light-cure resin cement (NX3 from Henry Schein). Mice started behavioral training $\sim 3-4$ weeks after surgery and were tested/recorded $\sim 6-9$ weeks after surgery.

\section{Imaging of viral-mediated gene expression}

Mice were perfused transcardially with $0.1 \mathrm{M}$ PBS followed by $4 \%(\mathrm{w} / \mathrm{v})$ paraformaldehyde in PBS. Brains were removed carefully and given an additional $48 \mathrm{~h}$ postfix in $4 \%$ paraformaldehyde, and then transferred to $30 \%$ sucrose in PBS for $48 \mathrm{~h}$ before sectioning. Coronal or sagittal sections $(35 \mu \mathrm{m})$ were cut with a cryostat (Microm HM550). Sections were washed in PBS and mounted using Fluoromount-G mounting medium (Southern Biotech). Expression of enhanced yellow fluorescent protein (EYFP) and mCherry at the injection and projection sites were examined using an Olympus IX71 fluorescence microscope and images were taken at $4 \times$ or $10 \times$ original magnification using a QImaging camera and MetaMorph Advanced software. Fluorescent axons at the projection site (NAc) were further imaged under $60 \times$ magnification using an Olympus FV1200 IX83 confocal microscope and FV10 software. Optical sections were $\sim 5-6 \mu \mathrm{m}$ thick.

\section{In vitro electrophysiology}

NAc acute slice preparation. Mice for the SDe group were killed immediately following SDe at $\sim$ 1:30 P.M. Control mice remained in their home cages without disturbance and were also killed at $\sim 1: 30$ P.M., after $\sim 20$ min of arousal. Acute brain slices were prepared as described previously (Huang et al., 2009). Briefly, each mouse was deeply anesthetized with isoflurane and decapitated, and the brain was removed and sliced using a vibratome (Leica VT1200s) in $4^{\circ} \mathrm{C}$ cutting solution containing the following (in mM): $135 \mathrm{~N}$-methyl-D-glucamine, $1 \mathrm{KCl}, 1.2 \mathrm{KH}_{2} \mathrm{PO}_{4}, 0.5$ $\mathrm{CaCl}_{2}, 1.5 \mathrm{MgCl}_{2}, 20$ choline- $\mathrm{HCO}_{3}$, and 11 glucose, $\mathrm{pH}$ adjusted to 7.4 with $\mathrm{HCl}$, and saturated with $95 \% \mathrm{O}_{2} / 5 \% \mathrm{CO}_{2}$. Coronal (Figs. 2, 3) or sagittal slices (Fig. 4) of $200 \mu \mathrm{m}$ thickness were cut containing the NAc subregions. Slices were allowed to recover in oxygenated artificial cerebrospinal fluid (aCSF) [containing (in $\mathrm{mm}$ ) $119 \mathrm{NaCl}, 2.5 \mathrm{KCl}, 1$ $\mathrm{NaH}_{2} \mathrm{PO}_{4}, 1.3 \mathrm{MgCl}_{2}, 2.5 \mathrm{CaCl}_{2}, 26.2 \mathrm{NaHCO}_{3}$, and 11 glucose, 290 mOsm, saturated with $95 \% \mathrm{O}_{2} / 5 \% \mathrm{CO}_{2}$ ] first in $37^{\circ} \mathrm{C}$ for $15-20 \mathrm{~min}$ and then at room temperature for a total of $1-2 \mathrm{~h}$. For recordings, one slice was transferred from the holding chamber to a submerged recording chamber, where it was continuously perfused with oxygenated aCSF maintained at $31 \pm 1^{\circ} \mathrm{C}$.

Electrophysiological recordings. Slice recordings lasted for $4-5 \mathrm{~h}$ after preparation. Whole-cell voltage-clamp recordings were made under visual guidance $(40 \times$, infrared Dodt contrast imaging) from NAc neurons located in the dorsal-medial shell region. A patch electrode of 3-5 $\mathrm{M} \Omega$ was filled with $\mathrm{a} \mathrm{Cs}^{+}$-based internal solution containing the following (in $\mathrm{mm}$ ): 108 Cs-methanesulfonate, $15 \mathrm{CsCl}, 5$ tetraethylammonium chloride, 20 HEPES, 0.4 EGTA, 2.5 MgATP, 0.25 $\mathrm{Na}_{3} \mathrm{GTP}$, 1 QX-314, 7.5 phosphacreatine $\left(\mathrm{Na}_{2}\right)$, and $1 \mathrm{~L}$-glutathione, $\mathrm{pH}$ 7.25-7.30, $290 \mathrm{mOsm}$. Excitatory afferents were stimulated at $0.1 \mathrm{~Hz}$ by a constant-current isolated stimulator (DS3; Digitimer) using a monopolar electrode (glass pipette filled with aCSF) with a pulse duration of $0.1 \mathrm{~ms}$. For light-evoked responses, a transistor-transistor logic (TTL)-controlled laser light of 473 $\mathrm{nm}$ was delivered as $0.3-1 \mathrm{~ms}$ pulses through the $40 \times$ objective lens onto the slice. Stimulation of SSFO was achieved by a train of light pulses (10 pulses of $50 \mathrm{~ms}$ duration at $10 \mathrm{~Hz}$ ). The output at the objective lens was $\sim 10 \mathrm{~mW}$. At least $5 \mathrm{~min}$ of a stable baseline was recorded before data collection. In all recordings, series resistance was $8-15 \mathrm{M} \Omega$ and was left uncompensated. Series resistance was monitored continuously during all recordings, and a change beyond $\pm 15 \%$ resulted in exclusion of the cell from data analysis. Synaptic currents were recorded with a MultiClamp $700 \mathrm{~B}$ amplifier (Molecular Devices), filtered at $2.6-3 \mathrm{kHz}$, amplified five times, and then digitized at $20 \mathrm{kHz}$ with a Digidata $1440 \mathrm{~A}$ analog-todigital converter (Molecular Devices). Stimulus artifacts of electrical stimulations were truncated in presentation for clarity. Picrotoxin (100 $\mu \mathrm{M})$ was included in the bath in most recordings to inhibit $\mathrm{GABA}_{\mathrm{A}}$ receptor $\left(\mathrm{GABA}_{\mathrm{A}} \mathrm{R}\right)$-mediated responses. Tetrodotoxin $(1 \mu \mathrm{M})$ was bath applied when recording miniature ESPC (mEPSCs) or miniature IPSCs (mIPSCs). NBQX (5 $\mu \mathrm{M})$ was bath applied to block AMPA receptors (AMPARs; Fig. 2 E, F). Tetrodotoxin was purchased from Alomone Labs, QX-314 and NBQX were purchased from Tocris Bioscience, and all other reagents were purchased from Sigma-Aldrich.

Electrophysiological recordings were initially analyzed using Clampfit (version 9 or 10). For variance-mean (V-M) analysis (Fig. 3), the variance and mean amplitude were calculated for each of the five EPSCs in the train from $\sim 50-100$ consecutive sweeps. The parabola function is $y=A * X-B * X^{2}$, where $y$ is the variance and $X$ is the mean amplitude; $A$ and $B$ can thus be derived through fitting (Fig. 3, example curves). With mathematical assumptions and simplifications, the average quantal content $(Q)=A, N=1 / B$, and the $\operatorname{Pr}$ at a particular stimulus in the train is $P_{i}=X_{i} * B / A$. Pr at the first stimulus in the train was calculated for all projections under control and SDe conditions.

\section{In vivo optogenetics}

The optic fibers were attached with an FC/PC adaptor to a $473 \mathrm{~nm}$ blue laser (Shanghai Laser and Optics), which was TTL-controlled by a pulse generator (A-M Systems). Optic fiber light intensity was adjusted to $\sim 10$ $\mathrm{mW}$ at the ending of each branch. Before attaching the optic fibers to the head-mounted guide cannula, the mouse was briefly sedated with isoflurane to allow smooth insertion and to prevent damage to the optic fibers. The tips of the stripped optic fibers extended $1 \mathrm{~mm}$ beyond the tips of the guide cannula. A train of light pulses (10 pulses of $50 \mathrm{~ms}$ at $10 \mathrm{~Hz}$ ) was delivered bilaterally under anesthesia. We used a train of light pulses rather than sustained illumination because light pulses were sufficient to achieve our intended presynaptic manipulation while having less concern of tissue damage compared to sustained illumination. After the mouse was fully awake and mobile [ $\sim 8 \mathrm{~min}$ after light stimulation (LS)], the mouse was placed in the testing chamber. Control mice were also sedated with isoflurane over the same duration of time, and a sham optic fiber was attached to the head-mounted guide cannula. After the same time interval ( $\sim 8 \mathrm{~min})$, they were placed into the testing chamber. The mice underwent four testing conditions in a randomized counterbalanced manner: control (with brief anesthesia and optic fiber insertion), control with LS, SDe (with brief anesthesia and optic fiber insertion), SDe with LS. Baseline levels were the average from 3-4 d before each corresponding test.

\section{Statistical analysis}

All data were analyzed without prior awareness of the treatment (control or SDe; with or without light stimulation). Each experiment was replicated in at least five mice unless specified otherwise for electrophysiological analysis (approximately two to six cells recorded from each mouse), and 8-16 mice were used per group for behavioral analysis. Statistical analysis was performed using Prism GraphPad (version 6). Statistical significance was assessed using $t$ tests (for two-group comparisons; twotailed tests), one-way ANOVA (single factor multiple groups), or twoway repeated-measures (RM) ANOVA, followed by Bonferroni posttest. For two-factor ANOVA, factor A was assigned for the treatments (e.g., control vs SDe) and factor B was assigned for testing time. The statistical results are primarily presented in the $F$ and $p$ values of the main effect of factor $A$, which was the primary research interest. Degrees of freedom of between (b) and within (w) treatments are presented as $F_{(\mathrm{b}, \mathrm{w})}$. A value of $p<0.05$ was considered statistically significant. For all experiments 
A $\mathrm{mPFC}$

B
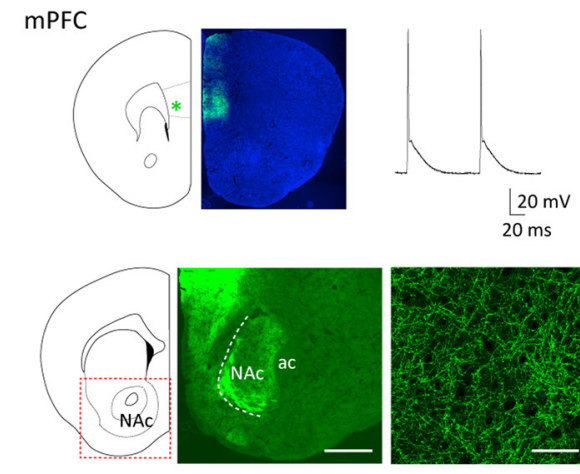

C
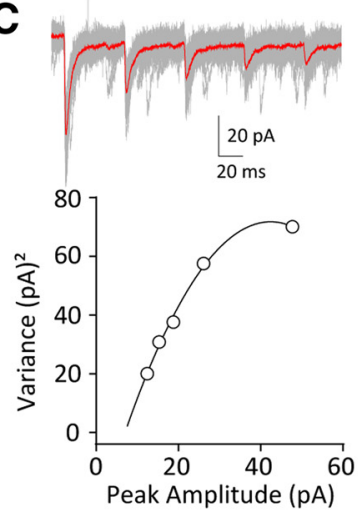

E

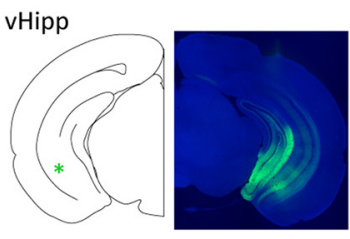

F

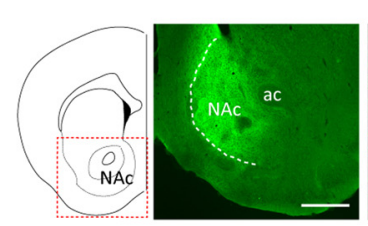

I

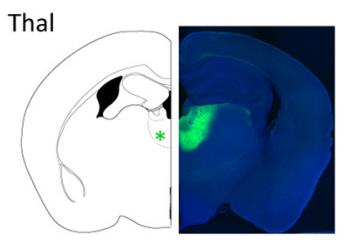

J

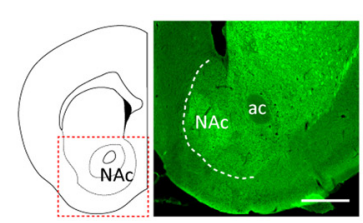

M

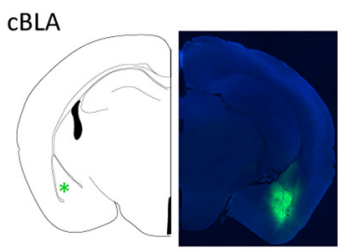

N

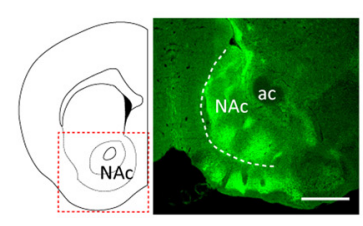

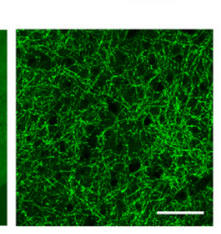

G

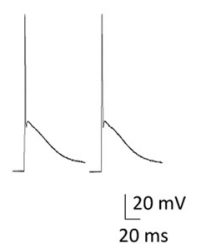

G $\sqrt{\substack{200 \mathrm{pA} \\ 20 \mathrm{~ms}}}$

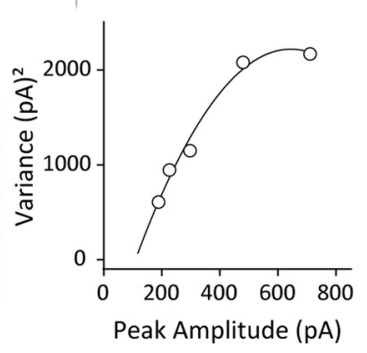

K
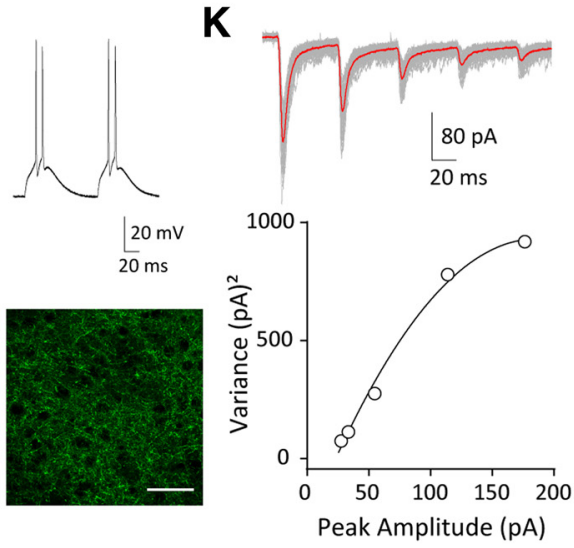

0
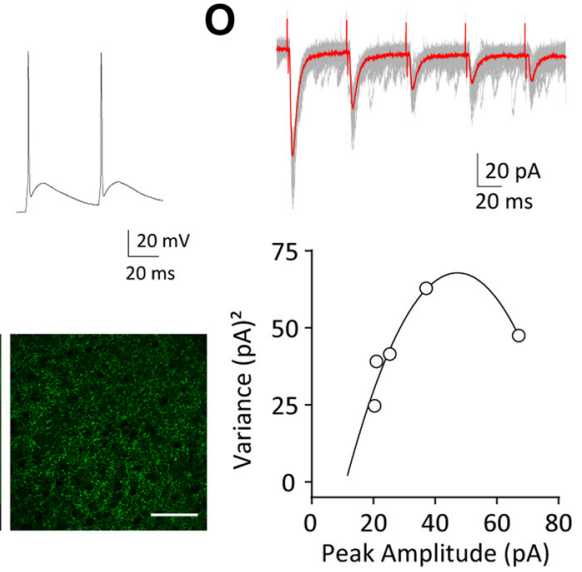

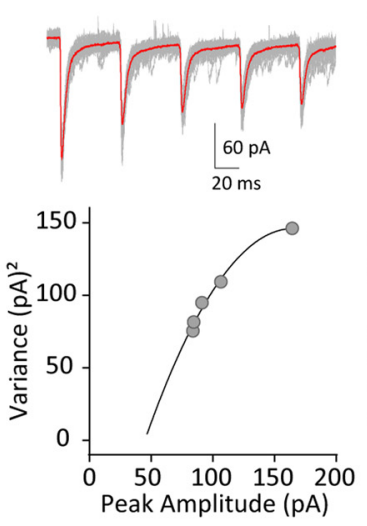

D

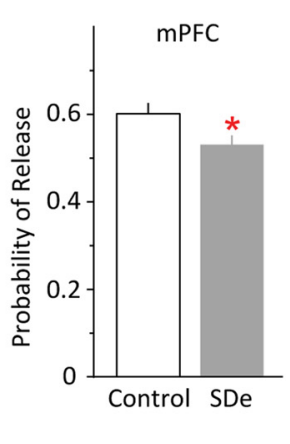

H
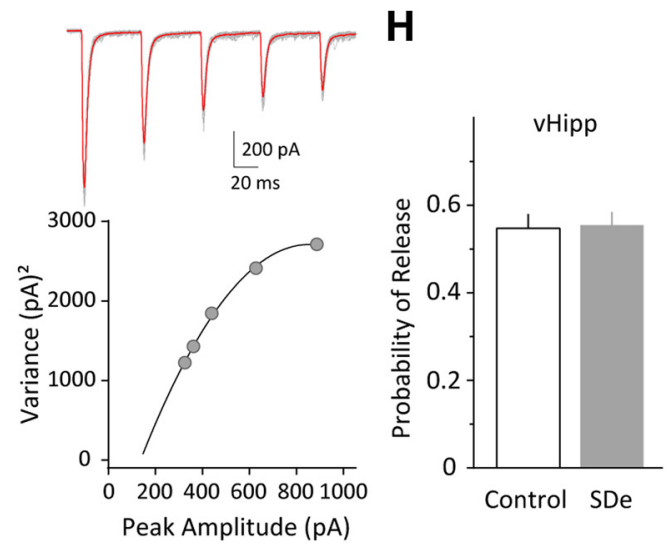

L
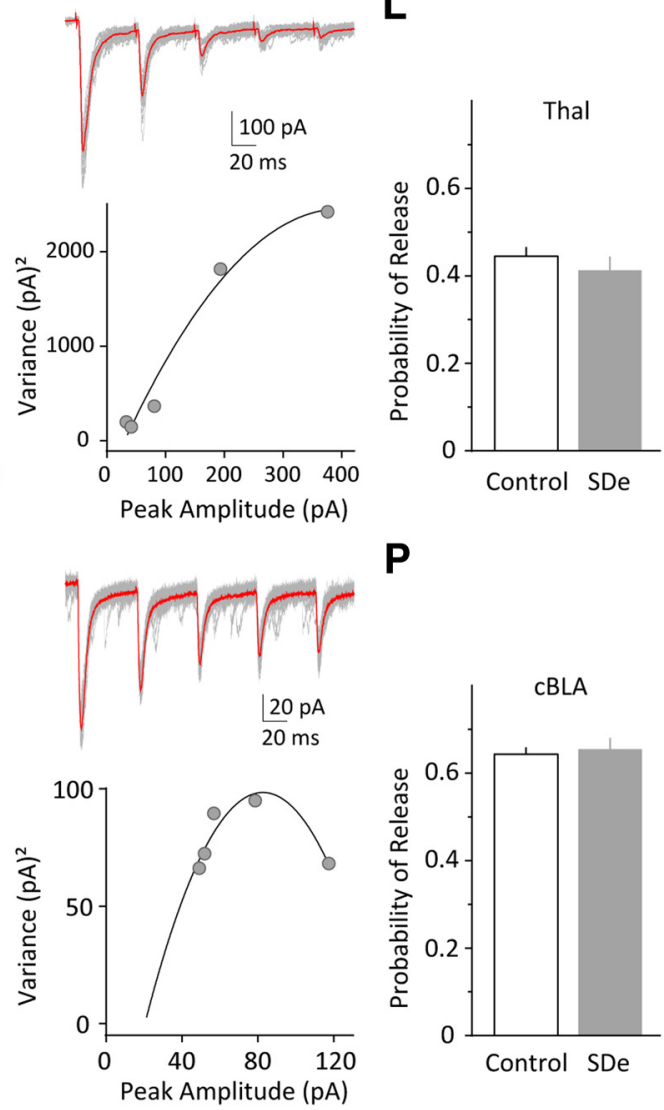

P
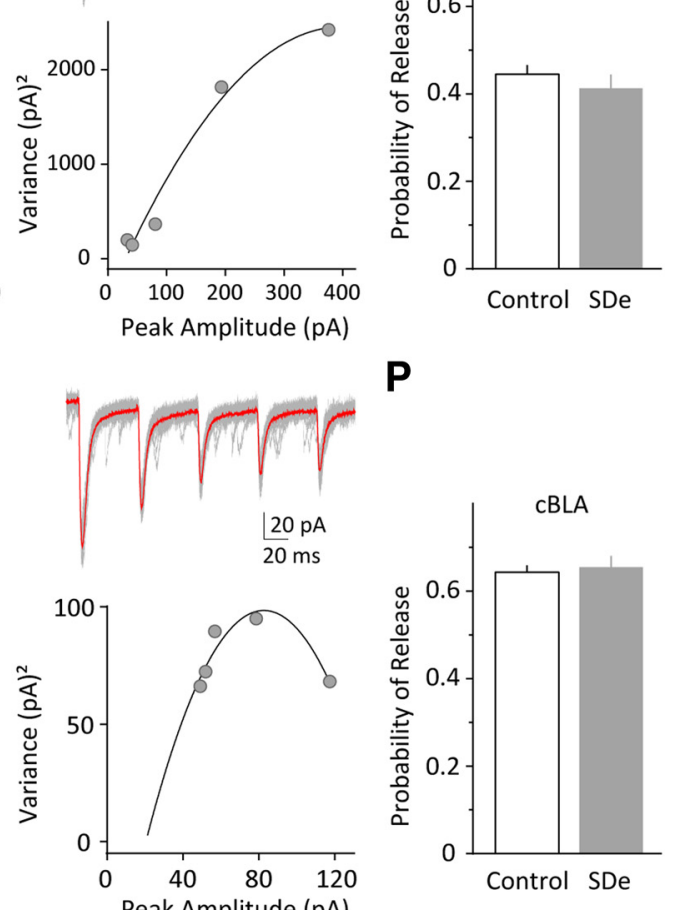

Figure 3. SDe selectively reduces the Prat mPFC-to-NAc synapses. $A, E, I, M, I$ mages showing the injection sites $\left({ }^{*}\right)$ of the viral vector AAV2-ChR2-EYFP and expression of ChR2-EYFP in the mouse $\mathrm{mPFC}(\boldsymbol{A})$, ventral hippocampus $(\boldsymbol{E})$, thalamus $(\boldsymbol{I})$, and $\mathrm{BLA}(\boldsymbol{M})$ on coronal brain sections. Right, Action potentials could be reliably evoked by $0.3-0.5 \mathrm{~ms}$ light pulses from cell soma located in the injection sites. $B, F, J, N$, Images under $4 \times$ and $60 \times$ magnifications showing the ChR2-EYFP-expressing axons projected into the NAc (coronal sections). Scale bars: Left, $500 \mu \mathrm{m}(4 \times)$ ); right, 50 $\mu \mathrm{m}(60 \times) . \boldsymbol{C}, \mathbf{G}, \boldsymbol{K}, \mathbf{O}$, Example AMPAR EPSCs evoked by a repeated train of light pulses (5 pulses of $0.5-1 \mathrm{~ms}$ at $20 \mathrm{~Hz}$ ) applied locally within the NAc, recorded from (Figure legend continues.) 
involving electrophysiology using behaviorally treated animals, both cell- and animal-based statistics were performed and reported, with numbers represented as $n=$ number of cells/number of animals. All values are represented as mean $\pm \mathrm{SEM}$.

\section{Results}

SDe enhances motivation for sucrose reward

To test how our gentle-handling SDe (see Materials and Methods) may affect the general behavioral states of the mice, we scored their voluntary behaviors under control conditions or SDe between 7:00 A.M. and 1:00 P.M. Under control conditions, the mice $(n=8)$ had mostly quiet time $(90.6 \pm 1.9 \%$ of total time), but also spent time exploring $(6.5 \pm 1.2 \%)$ and feeding $(2.9 \pm$ $1.0 \%)$ between bouts of sleep. Mice under SDe $(n=8)$ showed significantly reduced quiet time $(21.9 \pm 3.8 \%$ of total time, $p<$ $0.001, t$ test $)$ and spent more time exploring $(66.4 \pm 2.9 \%, p<$ $0.001, t$ test $)$ and feeding $(11.6 \pm 1.2 \%, p<0.001, t$ test; Fig. $1 A)$. The increase in feeding likely reflects their increased energy expenditure, and it also suggests that our gentle-handling method minimally disturbs their natural voluntary behaviors.

To examine the efficacy of the gentle handling procedure on sleep, we recorded EEG and EMG signals from a separate group of mice $(n=6)$ underwent the same SDe treatment. As shown in Figure $1 B$, gentle-handling SDe effectively reduced, albeit not eliminated, the total sleep time (control, $157 \pm 9 \mathrm{~min}$; SDe, $36 \pm$ $3 \mathrm{~min} ; p<0.001$, paired $t$ test). The reduction was attributable to fewer numbers of sleep episodes (control vs SDe, NREM, $89.9 \pm$ 10.8 vs $38.4 \pm 4.2, p<0.01 ;$ REM, $23.8 \pm 2.2$ vs $6.3 \pm 3.6, p<$ 0.01 ; paired $t$ test) as well as shortened durations of individual episodes (control vs SDe, NREM, $94.2 \pm 11.0 \mathrm{~s}$ vs $54.7 \pm 4.75 \mathrm{~s}$, $p<0.05$; REM, $58.3 \pm 5.70 \mathrm{~s}$ vs $26.0 \pm 8.08 \mathrm{~s}, p<0.05$; paired $t$ test). These results verify the efficacy of our gentle-handling SDe in reducing sleep.

During recovery sleep following SDe, the mice showed significant rebound in both NREM and REM sleep time (NREM, $F_{(1,5)}=8.41, p<0.05$; REM, $F_{(1,5)}=8.87, n=6, p<0.05$; two-way RM ANOVA; Fig. 1C). In addition, during the first hour of recovery sleep, there was significant rebound of NREM delta power in the $0.5-4.0 \mathrm{~Hz}$ range $\left(F_{(1,5)}=11.14, p<0.05\right.$, two-way RM ANOVA; Fig. 1D), suggesting enhanced slow-wave activity during recovery sleep. These results demonstrate that our gentlehandling SDe induces sufficient sleep debt, which leads to clear sleep rebound after SDe, as expected based on previous studies (Fenzl et al., 2007).

To test the extent to which our SDe method causes stress to the mice, we measured the plasma corticosterone levels following $\mathrm{SDe}$, which is commonly used to assess SDe-induced stress ( $\mathrm{Su}-$ checki et al., 1998; Kopp et al., 2006; Palchykova et al., 2006; Colavito et al., 2013). As a positive control, we included a group of mice with acute physical restraint, a known stressful condition. As shown in Figure 1E, mice after SDe did not have significantly altered corticosterone levels compared to the control group after normal sleep ( $n=8$ each group, $p=0.842$, Bonferroni posttest,

(Figure legend continued.) NAc MSNs at $-70 \mathrm{mV}$ in the presence of picrotoxin $(100 \mu \mathrm{m})$ from mice after control sleep (left) or SDe (right). Averaged traces are shown in red. The corresponding variance-mean plots (bottom) from the EPSC trains were used to generate the parabolic fittings (solid lines) and to estimate the $\operatorname{Pr}$. D, H, L, P, Summarized results showing decreased $\mathrm{Pr}$ within the mPFC-NAc pathway following SDe (D), but not in hippocampus-NAc, thalamus$N A c$, or CBLA-NAc pathways $(\boldsymbol{H}, \boldsymbol{L}, \boldsymbol{P}$, respectively). $n=11-18$ cells per group from $2-5$ mice each. ${ }^{*} p<0.05$ (compared to mice without SDe). All values are represented as mean \pm SEM. ac, anterior commissure; Thal, thalamus; vHipp, ventral hippocampus. one-way ANOVA), whereas those receiving acute physical restraint had significantly elevated corticosterone levels $(n=7, p<$ 0.001 , Bonferroni posttest). Furthermore, both control (awakened 20 min before test) and SDe groups were within the normal range typically observed in male mice around this time of day (Kakihana and Moore, 1976; Barriga et al., 2001; Malisch et al., 2008). These results are consistent with previous reports showing minimal stress induced by the gentle-handling SDe procedure (Kopp et al., 2006; Palchykova et al., 2006). Together, the above results suggest that our gentle-handling SDe method effectively reduces sleep with low stress liability.

To understand the behavioral consequences of SDe on reward, we tested sucrose self-administration (see Materials and Methods) in mice after various sleep manipulations. As shown in Figure $1 F$, following SDe, mice achieved a significantly higher number of active-lever presses for sucrose pellets compared to the baseline, which recovered $1 \mathrm{~d}$ after SDe $\left(F_{(2,30)}=17.99, n=\right.$ $16, p<0.001$, one-way RM ANOVA; control vs SDe, $p<0.001$; control vs recover, $p>0.999)$; the inactive-lever pressing remained at the baseline low level $\left(F_{(2,30)}=1.485, p=0.243\right.$, oneway RM ANOVA), suggesting that the increase in active-lever pressing was not due to a general increase in nonspecific lever pressing. The mice also obtained more sucrose pellets following SDe, which returned to the baseline level $1 \mathrm{~d}$ after $\operatorname{SDe}\left(F_{(2,30)}=\right.$ 19.45, $n=16, p<0.001$, one-way RM ANOVA; control vs SDe, $p<0.001$; control vs recover, $p=0.887$; Fig. $1 G)$. Detailed analysis in $5 \mathrm{~min}$ bins revealed that the higher level of active-lever pressing on the SDe day was evident throughout the 30 min test (SDe by time interaction, $F_{(6,90)}=13.54, p<0.001$; main effect of SDe, $F_{(1,15)}=22.69, p<0.001$; main effect of time, $F_{(6,90)}=$ $240.8, p<0.001$, two-way RM ANOVA; $p<0.01$ or less at $5-30$ min, control vs SDe, Bonferroni posttests; Fig. $1 H$ ). In addition, mice on the SDe day first approached the active lever sooner than on the baseline days, thus exhibiting shortened latencies; the effect returned to the baseline level $1 \mathrm{~d}$ after $\operatorname{SDe}\left(F_{(2,30)}=7.982\right.$, $n=16, p<0.01$, one-way RM ANOVA; control vs SDe, $p<$ 0.001 ; control vs recover, $p=0.393$; Fig. $1 I$ ). These results suggest that SDe reversibly enhances reward seeking and taking.

The shortened latency for active-lever pressing, before any sucrose pellet was delivered, suggests the possibility of enhanced motivation to obtain reward. To test this possibility, we ran a 5 min test for active-lever pressing without actual delivery of sucrose pellets. Compared to the baseline days, mice after SDe had significantly higher numbers of active-lever pressing (SDe by time interaction, $F_{(5,45)}=8.848, p<0.001$; main effect of SDe, $F_{(1,9)}=7.270, n=10, p<0.05$; main effect of time, $F_{(5,45)}=$ 63.61, $p<0.001$; two-way RM ANOVA; Fig. $1 J)$, consistent with enhanced motivation for reward.

Finally, to understand the extent to which SDe preferentially enhances reward (sucrose) seeking over general food consumption, we separately tested their free consumptions of either sucrose or grain-based food pellets after various sleep manipulations (see Materials and Methods). Interestingly, while mice consistently showed increases in sucrose pellet consumption following $\operatorname{SDe}\left(F_{(2,22)}=49.47, n=12, p<0.001\right.$, Bonferroni posttest, one-way RM ANOVA), their food pellet consumption, tested independently, was decreased following SDe compared to the baseline days $\left(F_{(2,22)}=9.133, n=12, p<0.01\right.$, Bonferroni posttest, one-way RM ANOVA). Both effects returned to the baseline levels after recovery sleep (control vs recovery, sucrose, $p=0.895$; food, $p=0.889$, Bonferroni posttest; Fig. $1 K$ ). These results suggest that the increase in sucrose seeking and consumption was not likely attributable to increased hunger following 
SDe. Indeed, since the mice had ad libitum access to food and water during SDe, and because they spent much more time feeding during SDe than under control conditions (Fig. 1A), they were likely to be less hungry following SDe, which is reflected in the decreased food consumption after SDe (see Discussion). Together, the contrasting results between sucrose and food consumptions following SDe further suggest that SDe selectively enhances motivation for sucrose reward.

\section{SDe reduces glutamatergic transmission onto NAc medium spiny neurons}

To understand the neural mechanisms of the SDe effects on reward seeking, we focused on the NAc. The principle neurons of the NAc are the medium spiny neurons (MSNs). Lacking intrinsic pace-making mechanisms, MSNs rely primarily on the integration of excitatory and inhibitory synaptic inputs to generate functional output. Glutamatergic transmission in the NAc has been known to process reward valence and regulate various types of reward seeking, including natural reward and drug reward (Maldonado-Irizarry et al., 1995; Cornish and Kalivas, 2000; Kalivas, 2009; Faure et al., 2010). We first tested whether the balance between the excitatory synaptic input and the inhibitory input is altered in NAc MSNs by SDe. Immediately after $6 \mathrm{~h}$ of SDe, AMPAR-mediated EPSCs and $\mathrm{GABA}_{\mathrm{A}} \mathrm{R}$-mediated IPSCs were isolated pharmacologically. As shown in Figure 2, $A$ and $B$, the ratio of the peak amplitude of AMPAR EPSCs over $G_{A B A} R$ IPSCs (AMPA/GABA ratio) was significantly decreased following SDe, which recovered after $1 \mathrm{~d}\left(F_{(2,61)}=15.74, n=17-24\right.$ cells per group from 8-11 mice each, $p<0.001$, one-way ANOVA; control vs SDe, $p<0.001$; control vs recover, $p>0.999)$. These results indicate a reversible decrease in the E/I ratio of synaptic inputs onto NAc MSNs after SDe.

A decrease in the E/I ratio suggests a decrease in excitatory transmission and/or an increase in inhibitory transmission, and these changes can be expressed either presynaptically or postsynaptically. To test presynaptic alterations, we evoked paired responses in close successions and examined the paired-pulse ratio (PPR) of the peak amplitudes of the responses. A presynaptic reduction in the Pr could be revealed as a reduction in the first response relative to the second response, and thus an increase in the PPR (second/first response). As shown in Figure 2, $C$ and $D$, SDe significantly increased the PPR of AMPAR EPSCs, which recovered $1 \mathrm{~d}$ after $\operatorname{SDe}\left(F_{(2,54)}=6.317, n=16-21\right.$ cells per group from 6-7 mice each, $p<0.01$, one-way ANOVA; control vs SDe, $p<0.01$; control vs recover, $p>0.999)$. Thus, it appears that SDe reduced presynaptic glutamate release onto the NAc MSNs.

If presynaptic glutamate release was reduced, then NMDA receptor (NMDAR) EPSCs should also exhibit an increase in PPR. As predicted, the PPR of NMDAR EPSCs was also increased following SDe (control, $0.87 \pm 0.06, n=15 / 7$; SDe, $1.01 \pm 0.04$, $n=15 / 6, p<0.05 ; t$ test; Fig. $2 E$ ). Finally, the increase in PPR was only observed in EPSCs but not IPSCs (control, $0.71 \pm 0.04, n=$ $16 / 6$; SDe, $0.75 \pm 0.02, n=16 / 6, p=0.41$; $t$ test; Fig. $2 F$ ). These results suggest that the presynaptic effects of SDe are only expressed at glutamatergic synapses.

To examine postsynaptic alterations, we recorded mEPSCs and mIPSCs in NAc MSNs in mice with or without SDe. No changes in the amplitudes of mEPSCs or mIPSCs were detected following SDe (mEPSC, control, $19.46 \pm 0.56 \mathrm{pA}, n=35 / 6$; SDe, $20.60 \pm 0.62 \mathrm{pA}, n=35 / 5, p=0.19 ;$ mIPSC, control, $49.38 \pm$ $1.76 \mathrm{pA}, n=17 / 6$; SDe, $53.65 \pm 1.81 \mathrm{pA}, n=19 / 5, p=0.10 ; t$ test), suggesting no overall postsynaptic changes. However, the frequency of mEPSCs and mIPSCs also did not show difference in sleep-deprived mice (mEPSC, control, $6.60 \pm 0.68 \mathrm{~Hz}, n=35 / 6$; SDe, $6.02 \pm 0.57 \mathrm{~Hz}, n=35 / 5, p=0.53$; mIPSC, control, $3.21 \pm$ $0.39, n=17 / 6$; SDe, $5.32 \pm 1.14, n=19 / 5, p=0.09$; $t$ test), suggesting that the changes in glutamate release described above could involve only a subset of synapses - synapses that have either a relatively low number of active release sites and/or a low Pr. Together, these results suggest a lack of postsynaptic alterations in the NAc MSNs following SDe and that the SDe-induced presynaptic changes may be pathway specific.

To obtain further insight into the pathway specificity, we first examined SDe-induced changes in AMPAR EPSCs in dopamine $D_{1}$ versus $D_{2}$ receptor-expressing $\left(D_{1} R\right.$ vs $\left.D_{2} R\right)$ MSNs in the NAc. These two subtypes of MSNs exhibit certain degrees of anatomical and functional segregations, including synaptic innervations by glutamatergic inputs (MacAskill et al., 2012) and dopamine-mediated signaling (Gerfen and Surmeier, 2011). A shift in the balance of $D_{1} R$ and $D_{2} R$ MSN activity alters the functional output of the NAc, which has been shown to bidirectionally regulate reward-elicited behaviors (Lobo et al., 2010; Lobo and Nestler, 2011; Yawata et al., 2012). We recorded from Drd1atdTomato mice where $\mathrm{D}_{1} \mathrm{R}$ MSNs are genetically tagged with tdTomato; previous studies have shown reliable detections of $D_{1} R$ versus $D_{2} R$ MSNs in the NAc based on the tdTomato fluorescence signals (Shuen et al., 2008; Grueter et al., 2013). As shown in Figure 2, $G$ and $H$, SDe reduced the AMPA/GABA ratio in tdTomato-positive (operationally defined as $\mathrm{D}_{1} \mathrm{R}$ ) MSNs (control, $1.34 \pm 0.12, n=16 / 7$; SDe, $0.84 \pm 0.11, n=13 / 5 ; p<$ $0.01, t$ test) as well as increased the AMPAR EPSC PPR (control, $1.05 \pm 0.05, n=22 / 8$; SDe, $1.24 \pm 0.06, n=13 / 5 ; p<0.05$, $t$ test). Similarly, tdTomato-negative (operationally defined as $\mathrm{D}_{2} \mathrm{R}$ ) MSNs also exhibited SDe-induced decrease in AMPA/GABA ratio (control, $1.58 \pm 0.19, n=12 / 7$; SDe, $0.74 \pm 0.07, n=15 / 5$; $p<0.001, t$ test) and increased the AMPA EPSC PPR (control, $0.97 \pm 0.04, n=18 / 7$; SDe, $1.16 \pm 0.05, n=20 / 5 ; p<0.05$, $t$ test; Fig. $2 I, J)$. In addition, the PPR of GABAR IPSCs was not altered by SDe in $\mathrm{D}_{1} \mathrm{R}$ MSNs (control, $0.80 \pm 0.05, n=21 / 8$; SDe, $0.79 \pm$ $0.03, n=14 / 5 ; p=0.833, t$ test) or $\mathrm{D}_{2} \mathrm{R}$ MSNs (control, $0.80 \pm$ 0.04, $n=17 / 8$; SDe, $0.79 \pm 0.03, n=20 / 5 ; p=0.793, t$ test), suggesting that there was no change in presynaptic release at GABAergic synapses. Thus, SDe influences synaptic transmission to NAc $D_{1} R$ and $D_{2} R$ MSNs in a similar manner.

\section{SDe selectively decreases the Pr at mPFC-to-NAc synapses}

We then focused on glutamate transmission within the presynaptically defined pathways. The NAc does not contain local glutamatergic neurons. The glutamatergic inputs to the MSNs are longprojecting axons from multiple brain regions including the $\mathrm{MPFC}$, hippocampus, thalamus, and BLA, which are highly responsive to sleep and sleep loss (Muzur et al., 2002; Marshall and Born, 2007; Yoo et al., 2007; David et al., 2013). To examine presynaptic alterations in a pathway-specific manner, we injected AAV vectors expressing ChR2-EYFP into one of these locations each time and measured the Pr of projection-specific glutamate release onto NAc MSNs under control conditions or following SDe. As shown in Figure 3, 6-8 weeks after the viral injection, there was robust expression of EYFP and functional ChR2 at the sites of injections, as well as abundant ChR2-EYFP-expressing fibers in the NAc (Fig. $3 A, B, E, F, I, J, M, N)$, indicating direct projections. Light pulses of $0.5-1 \mathrm{~ms}$ applied to the NAc selectively activated the intended presynaptic input onto the MSNs (Fig. $3 C, G, K, O$ ), allowing pathwayspecific analysis of presynaptic release.

To quantify the Pr within different projections, we performed the optogenetically based nonstationary V-M analysis (see Ma- 
terials and Methods), which uses optical stimulations to isolate projections of interest and then estimates the quantal parameters of transmitter release based on the size and variability of the postsynaptic responses (Clements and Silver, 2000; Silver, 2003; Saviane and Silver, 2007; Huang et al., 2011; Suska et al., 2013). A train (five pulses of $0.1 \mathrm{~ms}$ at $20 \mathrm{~Hz}$ ) of stimuli induced a train of EPSCs in NAc MSNs (Fig. 3C, G, K,O). Over repeated stimulations, each EPSC within the train should stabilize at a specific $\mathrm{Pr}$, and the five EPSCs combined would represent the same set of synapses undergoing five different Prs, thus allowing the V-M analysis (Meyer et al., 2001; Scheuss and Neher, 2001; Scheuss et al., 2002). EPSC V-M plot was generated by calculating the mean and variance of the peak amplitude for each of the five EPSCs within the train. The V-M plot was then fitted with a parabola and interpreted assuming binomial statistics of transmitter release (Quastel, 1997; Silver, 2003). Under control conditions, synapses within the four projections exhibited different Prs $\left(F_{(3,56)}=11.42, p<0.001\right.$, one-way ANOVA $)$. Following SDe, there was a selective reduction of $\mathrm{Pr}$ at the mPFC-to-NAc synapses (control, $0.60 \pm 0.02, n=17 / 4$; SDe, $0.53 \pm 0.02, n=16 / 6$, $p<0.05, t$ test; Fig. $3 C, D)$, but not the hippocampus-to-NAc (control, $0.55 \pm 0.03, n=15 / 2$; SDe, $0.56 \pm 0.03, n=18 / 3, p=$ $0.86, t$ test; Fig. $3 G, H$ ), thalamus-to-NAc (control, $0.45 \pm 0.02$, $n=14 / 5$; SDe, $0.41 \pm 0.03, n=18 / 5, p=0.43$, $t$ test; Fig. $3 K, L)$, or cBLA-to-NAc synapses (control, $0.64 \pm 0.02, n=14 / 3$; SDe, $0.66 \pm 0.02, n=11 / 2, p=0.71, t$ test; Fig. $3 O, P)$. These results suggest that SDe selectively affects the $\mathrm{mPFC}$-to-NAc projections to reduce presynaptic glutamate release in the NAc.

\section{Reversing SDe-induced synaptic effects reverses SDe-induced increase in reward seeking}

Does reduced glutamate release within the mPFC-to-NAc projection contribute to enhanced reward seeking after SDe? To address this question, we experimentally strengthened glutamate release in this projection and examined the behavioral consequences. Specifically, we injected AAVs expressing SSFOmCherry into the mPFC (Fig. 4A). SSFO is a mutant form of ChR2, with sustained channel activity (deactivation $\tau, \sim 29 \mathrm{~min}$ ) following light activation, which typically induces a modest but persistent (>40 min) depolarizing current (Yizhar et al., 2011). We first tested whether SSFO activation at the nerve terminals would facilitate transmitter release. In NAc-containing sagittal slices prepared 6-8 weeks after intra-mPFC viral injection, the SSFO-mCherry-expressing fiber tracks could be clearly identified in the NAc (Fig. 4B,C). We then delivered paired-pulse electrical stimulations to the mCherry-expressing fiber track to preferentially recruit the mPFC-to-NAc afferents, meanwhile recording from a neuron along the track (Fig. 4C). A single train of LS centered upon the fiber track persistently enhanced the peak amplitude of the electrically evoked EPSCs in SSFO-expressing slices, compared to control slices that lacked SSFO expression/ activation (LS by time interaction, $F_{(52,988)}=1.466, p<0.05$; main effect of LS, $F_{(2,38)}=303.9, n=9-19, p<0.001$, two-way RM ANOVA). The light train stimulation also reduced the PPR in SSFO-expressing slices (second response/first, main effect of LS, $F_{(2,28)}=4.590, n=9-12, p<0.05$, two-way RM ANOVA; Fig. $4 D, E)$, suggesting increased $\mathrm{Pr}$. These results verify that a brief light activation of SSFO at mPFC-NAc terminals induces prolonged enhancing effects on action potential-dependent transmission, likely by increasing the Pr.

To test whether SSFO activation directly evokes presynaptic release of glutamate, we recorded EPSCs during the LS train in the absence of electrical stimulations and measured the peak am- plitude and charge transfer during LS. To ensure detection sensitivity, only the positive responders to SSFO activation from Figure $4 E$ were included in this analysis. As shown in Figure $4 F$, the EPSCs during LS ( $1 \mathrm{~s}$ ) did not show increased peak amplitude (baseline, $33.98 \pm 2.56 \mathrm{pA}$; LS, $34.02 \pm 2.93 \mathrm{pA} ; n=15 ; p=$ 0.986 , paired $t$ test) or charge transfer (baseline, $1.58 \pm 0.31$ $\mathrm{pA}^{*} \mathrm{~s}$; LS, $1.58 \pm 0.30 \mathrm{pA}^{\star} \mathrm{s} ; n=15 ; p=0.950$, paired $t$ test) compared with the baseline spontaneous EPSCs (10 s average before LS). Together, these results suggest that activation of axonal SSFO does not directly evoke transmitter release, but can facilitate endogenous action potential-dependent transmitter release. This feature is potentially important to minimize the activation of axons bypassing the stimulation target area, and is thus advantageous for in vivo applications.

We then applied the SSFO approach in vivo to test whether strengthening glutamate transmission in the mPFC-to-NAc projection would normalize SDe-induced reward seeking. Mice received intra-mPFC injection of AAV2-SSFO-mCherry and bilateral guide cannula implantation just above the NAc (Fig. $4 G)$. The mice then underwent sucrose self-administration training and tests under four different conditions over the following 6-9 weeks (Fig. 4G). Because of minor fluctuations in the baseline performance during the 4 week testing period, we present both the baseline and the testing active-lever pressings, and used the ratio for statistics. As shown in Figure $4 H$, the active-lever pressing showed a significant interaction between SDe and LS $\left(F_{(1,56)}=5.291, n=15\right.$ each group, $p<0.05$, two-way ANOVA). Specifically, SDe increased active-lever pressing (control vs SDe, $p<0.01$, Bonferroni posttest); following SDe, LS at mPFC-NAc terminals significantly reduced lever pressing for sucrose (SDe vs SDe + LS, $p<0.001$, Bonferroni posttest). Importantly, LS alone did not significantly affect active-lever pressing (control vs control + LS, $p=0.284$, Bonferroni posttest), suggesting that LS alone did not suppress baseline sucrose seeking. Finally, in the presence of LS, SDe did not further enhance active-lever pressing (control + LS vs SDe + LS, $p>0.999$, Bonferroni posttest), suggesting that LS prevented the SDe effect in enhancing sucrose seeking. The number of sucrose pellets obtained by the mice under different testing conditions followed the same patterns (control vs SDe, $p<0.05$; SDe vs SDe + LS, $p<0.001$; control vs control + LS, $p=0.186$; control + LS vs SDe + LS, $p>0.999$; Bonferroni posttest, two-way ANOVA; Fig. 4I). Furthermore, the number of inactive-lever presses was not significantly different in any of the four testing conditions (SDe by LS interaction, $F_{(1,56)}=1.709, p=0.197$; main effect of SDe, $F_{(1,56)}=1.284, p=$ 0.262 ; main effect of LS, $F_{(1,56)}=0.654, p=0.422$; two-way ANOVA; Fig. $4 J$ ), suggesting that the LS-induced decrease in sucrose seeking after SDe was not because of a nonspecific suppression of lever pressing. Finally, we tested whether intra-NAc SSFO stimulation may also affect general food consumption. As shown in Figure $4 K$, LS did not alter the consumption of freely available food pellets following either normal sleep or SDe (SDe by LS interaction, $F_{(1,9)}=0.098, n=10$ each group, $p=0.761$; main effect of SDe, $F_{(1,9)}=2.939, p=0.121$; main effect of LS, $F_{(1,9)}=0.231, p=0.642$; control vs control + LS, $p>0.999$; SDe vs SDe + LS, $p>0.999$; Bonferroni posttest, two-way RM ANOVA), suggesting that LS did not suppress general feeding behaviors. Together, these results suggest that weakened mPFCto-NAc glutamate transmission following SDe contributes to enhanced sucrose self-administration; compensatorily strengthening glutamate transmission at mPFC-to-NAc synapses normalizes sucrose self-administration in mice and counteracts the SDe effect. 
A

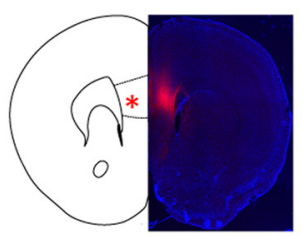

D

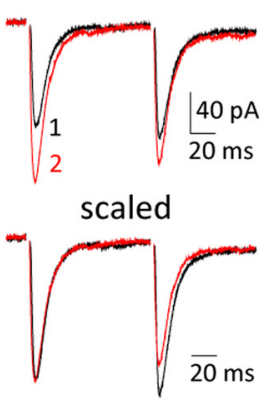

F

F Before
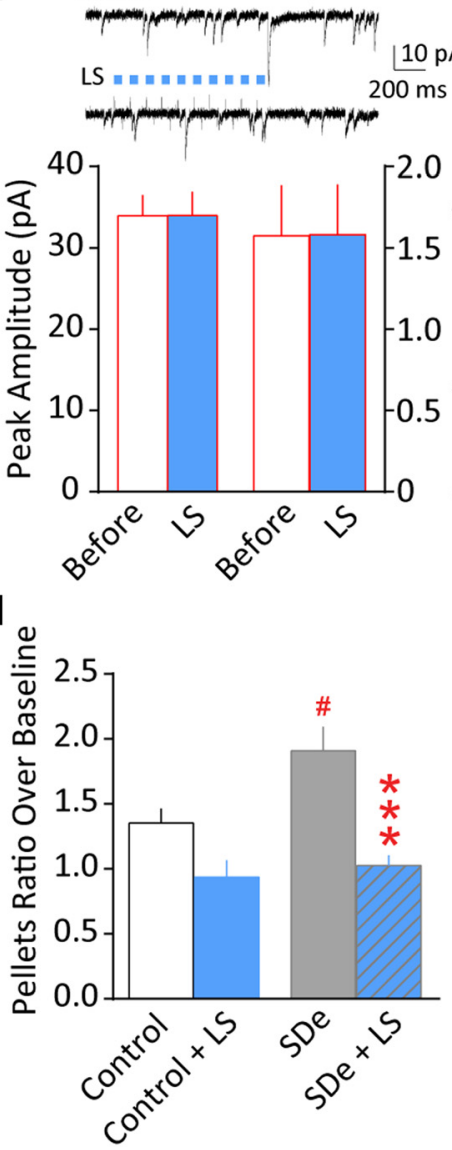

B

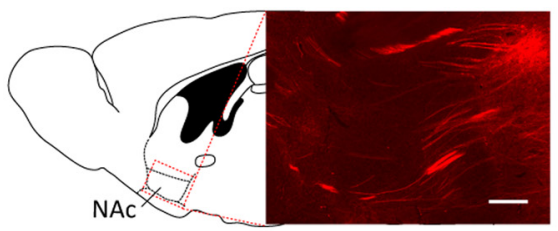

C

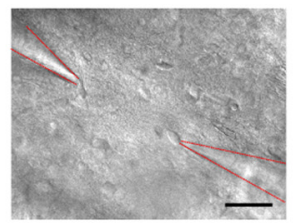

E
NAc

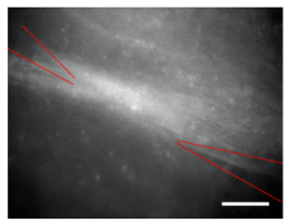

O Control O SSFO O SDe+SSFO
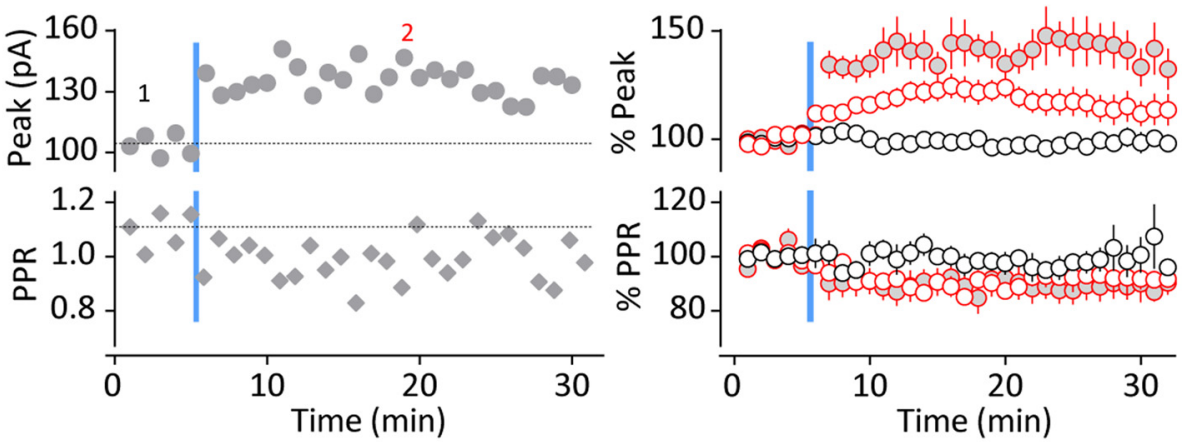

H

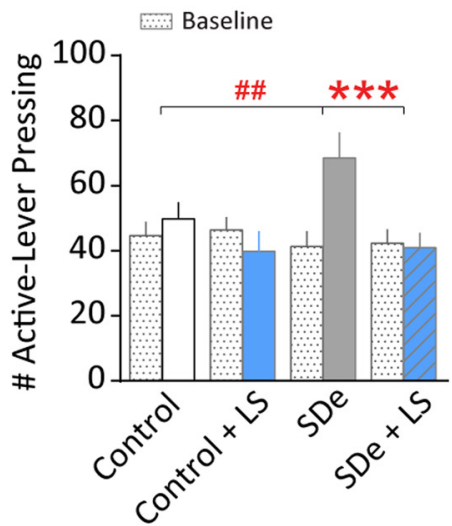

J

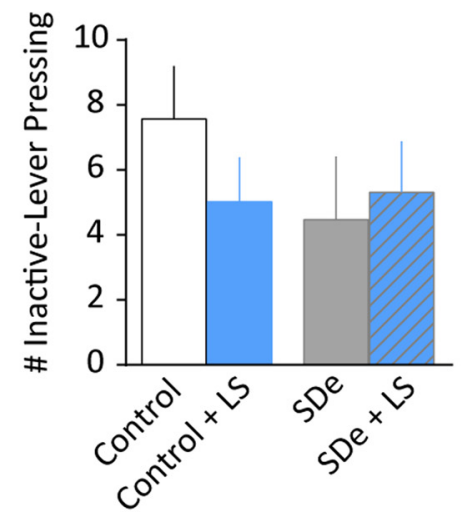

K

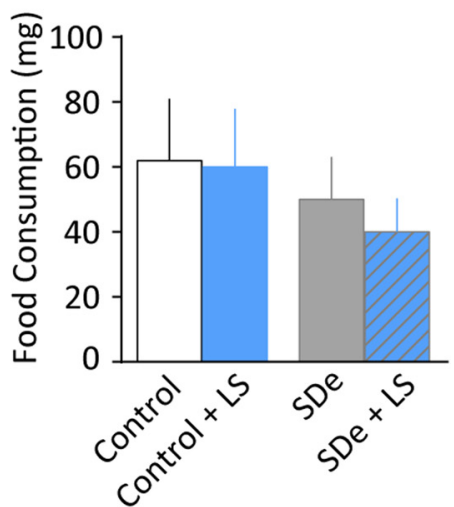

Figure 4. Activation of SSFO in mPFC-to-NAc projection enhances Pr and reduces sucrose seeking after SDe. A, Expression of AAV2-SSF0-mCherry at the $\mathrm{mPFC}$ injection site $\left({ }^{*}\right)$ on a coronal brain section. $\boldsymbol{B}$, Expression of SSFO-mCherry within an mPFC-to-NAc projection on a sagittal brain section. C, Dodt contrast (left) and fluorescence (right) images showing the recording configuration on a sagittal slice. The stimulating electrode was positioned on top of a fiber track that showed SSF0-mCherry expression, and recordings were made from an MSN in close proximity to the fiber track. D, Example AMPAR EPSCs evoked by paired-pulse stimulations (100 ms interpulse interval) in an NAc MSN before and after LS (10 pulses of $50 \mathrm{~ms}$ at $10 \mathrm{~Hz}$ ). Numbers 1 and 2 indicate when the averaged traces were recorded; blue lines indicate when the LS occurred. Traces 1 and 2 were scaled to the first peak to show the difference in PPR (bottom). E, Summarized results of evoked EPSC amplitude and PPR (normalized to the baselines before LS) showing enhanced EPSC peak amplitude following LS with the corresponding decrease in PPR. SSF0-expressing mice following either normal sleep (SSFO) or SDe (SDe + SSF0) were used, and the results were grouped accordingly. Slices without SSF0-mCherry expression but with LS and slices with SSF0-mCherry expression but without LS were pooled as the control group. Compared to the control, SSFO activation increased the peak amplitude $(n=9-19, p<0.001)$ and reduced the PPR of EPSCS $(n=9-12, p<0.05)$ at the mPFC-NAc afferents. $\boldsymbol{F}$, Example traces from the same neuron as in $\boldsymbol{D}$ and summarized results showing a lack of increase in either peak amplitude $(n=15, p=0.986)$ or charge transfer $(n=15, p=0.950)$ during the LS train. A $10 \mathrm{~s}$ baseline before LS was measured for peak amplitude (average of the peak amplitude of (Figure legend continues.) 


\section{Discussion}

SDe-associated changes in reward processing have been implicated in many pathological emotional and motivational conditions. Our present study shows that SDe induces a selective weakening of mPFC-to-NAc synapses, reversal of which ameliorates the impact of SDe on reward seeking. These results demonstrate of a causal relationship between sleep-induced neural adaptations and altered reward-seeking behavior. The results also exemplify a possibility of restoring SDe-induced abnormal reward seeking by restricted targeting of a specific neural projection, even though multiple reward-related brain regions are likely affected by SDe (Venkatraman et al., 2007, 2011; Gujar et al., 2011; Greer et al., 2013). Together, these results provide a circuitbased mechanism for understanding how sleep or sleep loss regulates reward-motivated behaviors.

\section{Selective enhancement of sucrose seeking following SDe}

We found that acute SDe led to an increase in sucrose seeking and consumption, with a contrasting decrease in food consumption after SDe (Fig. $1 K)$. A trend of decrease $(p=0.121)$ was also observed in Figure $4 K$ (control vs SDe). The reason for the reduced food intake after SDe was not clear. It is likely that the total food consumption was increased during SDe, as would be predicted by the approximately threefold increase in the feeding time (Fig. 1A). As a result, the mice may not be as hungry after SDe compared to after sleep, which then led to reduced food intake after SDe. Indeed, similar paradoxical changes have been observed in chronic REM sleep-deprived rats-their overall daily consumption of food is increased, but their motivation for food is decreased (Bhanot et al., 1989; Kushida et al., 1989; Hanlon et al., 2005, 2010; Koban et al., 2006). In contrast to the potential reduction of motivation for food, our results suggest that the motivation for sucrose reward was selectively enhanced in the mice following acute SDe. This is also consistent with previous reports that acute SDe enhances motivation for a variety of natural, artificial, and drug rewards (Steiner and Ellman, 1972; Brower et al., 1998; Killgore et al., 2006; McKenna et al., 2007; Venkatraman et al., 2007, 2011; Puhl et al., 2009, 2013; Gujar et al., 2011; Greer et al., 2013; Telzer et al., 2013).

\section{Reduced mPFC-to-NAc transmission following SDe}

The role of the mPFC in inhibitory top-down cognitive and emotional control has been well documented in various contexts, including regulation of impulsivity (Jentsch and Taylor, 1999; Chudasama et al., 2003; Murphy et al., 2005; Hare et al., 2009; Dalley et al., 2011; Etkin et al., 2011), addictive drug seeking and relapse (Peters et al., 2008; LaLumiere et al., 2012; Chen et al.,

\footnotetext{
(Figure legend continued.) each second) and charge transfer (average per second). For the LS condition, the peak amplitude and charge transfer were measured for the $1 \mathrm{~s}$ starting at $L S$ onset. G, Top, Schematic view of $\mathrm{mPFC}$ expression of SSF0-mCherry and LS in the NAc in vivo. Bottom, Timeline of surgery, training, and testing, including the order of events on the testing day. $\boldsymbol{H}$, Baselines and testing levels of active-lever pressing for sucrose pellets under the control condition (no SDe and no $L S$ ), control $+L S$, SDe (without $L S$ ), and SDe + LS. For statistics, all lever presses were normalized to the average of a $3 \mathrm{~d}$ baseline before each test. ${ }^{\#} p<0.01$ (compared to control); ${ }^{* * *} p<0.001$ (compared to SDe).I, Normalized sucrose pellets obtained under control, control + LS, SDe (without $L S$ ), and SDe + LS. All sucrose pellets were normalized to the average of a $3 \mathrm{~d}$ baseline before each test. ${ }^{\#} p<0.05$ (compared to control); ${ }^{* * *} p<$ 0.001 (compared to without LS). J, Inactive-lever pressing across the four testing conditions did not show significant difference. $n=15$ each group $(\boldsymbol{H}-\boldsymbol{J})$. $\boldsymbol{K}$, Consumption of freely available food pellets was not significantly altered by $L S$ either following control sleep or after SDe. $n=$ 10. All values are represented as mean \pm SEM. Scale bars: $\boldsymbol{B}, 200 \mu \mathrm{m} ; \boldsymbol{C}, 30 \mu \mathrm{m}$.
}

2013; Ma et al., 2014; Shen et al., 2016; Terraneo et al., 2016), and major depressive disorder (Wu et al., 1999; Gillin et al., 2001; Mayberg et al., 2005; Riga et al., 2014). Specifically, the frontostriatal projections have long been speculated to provide critical inhibitory control of the behavioral output of motivations (Jentsch and Taylor, 1999; Feil et al., 2010; Ferenczi et al., 2016).

SDe-induced "disinhibition" of mood and enhanced reward responding have been consistently observed, which are typically accompanied by reduced activity of the PFC (Pilcher and Huffcutt, 1996; Venkatraman et al., 2007; Greer et al., 2013). Furthermore, the antidepressant effects of SDe are often predicted by the amount of reduction of prefrontal cortical activity (Wu et al., 1999; Gillin et al., 2001). Our current results show that SDe selectively decreases the mPFC-to-NAc excitatory transmission (Fig. 3), which may contribute to a compromised top-down regulation of the subcortical affective drive to the NAc, unleashing reward-motivated behaviors. It is worth noting that depending on the subregions of $\mathrm{mPFC}$ and NAc, and experimental conditions, activation of the mPFC-to-NAc projection may also promote reinforcing behaviors (McFarland et al., 2003; Britt et al., 2012; Ma et al., 2014). Thus, the mPFC-to-NAc projection may play a multifaceted role, depending on the actual activation state and the involved circuits, in regulating reward seeking.

The molecular substrates that mediate the SDe-induced inhibition of glutamate transmission are not clear. A few potential candidates include adenosine, which accumulates during SDe (Huston et al., 1996; Porkka-Heiskanen et al., 2000), negatively regulates neural transmission in the NAc (Brundege and Williams, 2002a,b), and mediates SDe-induced antidepressant effects (Hines et al., 2013), and dopamine, whose signaling in the ventral striatum is dynamically regulated by sleep states (Volkow et al., 2012), modulates synaptic transmission in the NAc (Pennartz et al., 1992; Harvey and Lacey, 1996, 1997; Nicola and Malenka, 1998; Beurrier and Malenka, 2002; Tritsch and Sabatini, 2012; Wang et al., 2012), and impacts mood and reward seeking (Spanagel and Weiss, 1999; Nestler and Carlezon, 2006). Both adenosine and dopamine inhibit presynaptic glutamate release onto NAc MSNs at elevated concentrations. However, it is not known whether either exhibits pathway-selective sensitivities. Future studies will need to address the molecular, cellular, and anatomical substrates that mediate the selective reduction of $\mathrm{Pr}$ at mPFC-to-NAc synapses following SDe.

\section{SSFO-based facilitation of presynaptic release}

Activation of SSFO at the soma induces a moderate depolarizing current (Yizhar et al., 2011), whereas its function at the nerve terminals has not been well characterized. We observed that selective activation of SSFO at the nerve terminals enhanced the Pr persistently, but without evoking direct release of transmitters (Fig. 4D-F). These results suggest that the SSFO-induced modest depolarization facilitates, rather than triggers, action potentialdependent presynaptic release. This property provides several advantages over the use of ChR2 for enhancing transmission of selected projections in our experiments: (1) it increases the signal-to-noise ratio of endogenous release; (2) it enhances synaptic transmission, yet follows endogenous release patterns rather than superimposing an artificial release pattern; and (3) it minimizes the activation of bypassing axons as it is less likely to generate action potentials on its own.

The magnitude of facilitation of transmitter release is, however, dependent on the expression level of SSFO, the stimulation paradigm, and the quantal parameters of selected projections. As shown in Figure 4, $D$ and $E$, the facilitation of glutamate release 
reached a plateau $\sim 5-10 \mathrm{~min}$ after light stimulation, even though SSFO is immediately activated upon light stimulation (Yizhar et al., 2011). Such a delay suggests secondary mechanisms being involved. For example, activation of SSFO may also cause $\mathrm{Ca}^{2+}$ accumulation, which also increases presynaptic Pr. While many more details are still needed to understand how SSFO facilitates synaptic release, our in vitro characterizations verified the stimulation paradigm and the time frame that allowed us to manipulate projection-specific presynaptic release in vivo in a relatively reliable manner.

\section{NAc and reward seeking: is there pathway specificity?}

Whereas the conventional view holds that different glutamatergic inputs into the NAc convey different reward-related information and affect different aspects of behaviors, it may not be always necessary to differentiate the excitatory afferents to discern the behavioral outcomes. For example, gross upregulation or downregulation of the E/I balance within the NAc is sufficient to decrease or increase food consumption, respectively (Maldonado-Irizarry et al., 1995; Kelley and Swanson, 1997; Stratford and Kelley, 1997; Stratford et al., 1998; Kelley, 2004). Moreover, it was shown previously that direct activation of any one of the main glutamatergic afferents within the NAc, or direct activation of NAc principle neuron population, promotes motivated behaviors (Britt et al., 2012, but see Qi et al., 2016). It thus raises the question whether enhanced reward seeking following SDe is because of an overall shift in the excitatory tone in the NAc or, rather, that an imbalance between specific excitatory inputs-a reduction in cortical cognitive control relative to subcortical affective drive into the NAc_-shapes the altered reward processing. Addressing this question will help us understand the anatomical and functional organization of NAc circuits in motivated behaviors.

\section{References}

Baldo BA, Kelley AE (2007) Discrete neurochemical coding of distinguishable motivational processes: insights from nucleus accumbens control of feeding. Psychopharmacology 191:439-459. CrossRef Medline

Barriga C, Martín MI, Tabla R, Ortega E, Rodríguez AB (2001) Circadian rhythm of melatonin, corticosterone and phagocytosis: effect of stress. J Pineal Res 30:180-187. CrossRef Medline

Beurrier C, Malenka RC (2002) Enhanced inhibition of synaptic transmission by dopamine in the nucleus accumbens during behavioral sensitization to cocaine. J Neurosci 22:5817-5822. Medline

Bhanot JL, Chhina GS, Singh B, Sachdeva U, Kumar VM (1989) REM sleep deprivation and food intake. Indian J Physiol Pharmacol 33:139-145. Medline

Britt JP, Benaliouad F, McDevitt RA, Stuber GD, Wise RA, Bonci A (2012) Synaptic and behavioral profile of multiple glutamatergic inputs to the nucleus accumbens. Neuron 76:790-803. CrossRef Medline

Brower KJ, Aldrich MS, Hall JM (1998) Polysomnographic and subjective sleep predictors of alcoholic relapse. Alcohol Clin Exp Res 22:1864-1871. CrossRef Medline

Brundege JM, Williams JT (2002a) Differential modulation of nucleus accumbens synapses. J Neurophysiol 88:142-151. Medline

Brundege JM, Williams JT (2002b) Increase in adenosine sensitivity in the nucleus accumbens following chronic morphine treatment. J Neurophysiol 87:1369-1375. Medline

Chen BT, Yau HJ, Hatch C, Kusumoto-Yoshida I, Cho SL, Hopf FW, Bonci A (2013) Rescuing cocaine-induced prefrontal cortex hypoactivity prevents compulsive cocaine seeking. Nature 496:359-362. CrossRef Medline

Chen B, Wang Y, Liu X, Liu Z, Dong Y, Huang YH (2015) Sleep regulates incubation of cocaine craving. J Neurosci 35:13300-13310. CrossRef Medline

Chudasama Y, Passetti F, Rhodes SE, Lopian D, Desai A, Robbins TW (2003) Dissociable aspects of performance on the 5-choice serial reaction time task following lesions of the dorsal anterior cingulate, infralimbic and orbitofrontal cortex in the rat: differential effects on selectivity, impulsivity and compulsivity. Behav Brain Res 146:105-119. CrossRef Medline

Cirelli C, Tononi G (2004) Sleep deprivation: basic science, physiology and behavior. Boca Raton, Florida: CRC.

Clements JD, Silver RA (2000) Unveiling synaptic plasticity: a new graphical and analytical approach. Trends Neurosci 23:105-113. CrossRef Medline

Colavito V, Fabene PF, Grassi-Zucconi G, Pifferi F, Lamberty Y, Bentivoglio M, Bertini G (2013) Experimental sleep deprivation as a tool to test memory deficits in rodents. Front Syst Neurosci 7:106. Medline

Cornish JL, Kalivas PW (2000) Glutamate transmission in the nucleus accumbens mediates relapse in cocaine addiction. J Neurosci 20:RC89. Medline

Dallaspezia S, Benedetti F (2015) Sleep deprivation therapy for depression. Curr Top Behav Neurosci 25:483-502. Medline

Dalley JW, Everitt BJ, Robbins TW (2011) Impulsivity, compulsivity, and top-down cognitive control. Neuron 69:680-694. CrossRef Medline

David F, Schmiedt JT, Taylor HL, Orban G, Di Giovanni G, Uebele VN, Renger JJ, Lambert RC, Leresche N, Crunelli V (2013) Essential thalamic contribution to slow waves of natural sleep. J Neurosci 33:19599_ 19610. CrossRef Medline

Etkin A, Egner T, Kalisch R (2011) Emotional processing in anterior cingulate and medial prefrontal cortex. Trends Cogn Sci 15:85-93. CrossRef Medline

Faure A, Richard JM, Berridge KC (2010) Desire and dread from the nucleus accumbens: cortical glutamate and subcortical GABA differentially generate motivation and hedonic impact in the rat. PLoS One 5:e11223. CrossRef Medline

Feil J, Sheppard D, Fitzgerald PB, Yücel M, Lubman DI, Bradshaw JL (2010) Addiction, compulsive drug seeking, and the role of frontostriatal mechanisms in regulating inhibitory control. Neurosci Biobehav Rev 35: 248-275. CrossRef Medline

Fenzl T, Romanowski CP, Flachskamm C, Honsberg K, Boll E, Hoehne A, Kimura M (2007) Fully automated sleep deprivation in mice as a tool in sleep research. J Neurosci Methods 166:229-235. CrossRef Medline

Ferenczi EA, Zalocusky KA, Liston C, Grosenick L, Warden MR, Amatya D, Katovich K, Mehta H, Patenaude B, Ramakrishnan C, Kalanithi P, Etkin A, Knutson B, Glover GH, Deisseroth K (2016) Prefrontal cortical regulation of brainwide circuit dynamics and reward-related behavior. Science 351:aac9698. CrossRef Medline

Gerfen CR, Surmeier DJ (2011) Modulation of striatal projection systems by dopamine. Annu Rev Neurosci 34:441-466. CrossRef Medline

Giedke H, Schwärzler F (2002) Therapeutic use of sleep deprivation in depression. Sleep Med Rev 6:361-377. Medline

Gillin JC, Buchsbaum M, Wu J, Clark C, Bunney W Jr (2001) Sleep deprivation as a model experimental antidepressant treatment: findings from functional brain imaging. Depress Anxiety 14:37-49. CrossRef Medline

Greer SM, Goldstein AN, Walker MP (2013) The impact of sleep deprivation on food desire in the human brain. Nat Commun 4:2259. Medline

Grueter BA, Robison AJ, Neve RL, Nestler EJ, Malenka RC (2013) $\Delta$ FosB differentially modulates nucleus accumbens direct and indirect pathway function. Proc Natl Acad Sci USA 110:1923-1928.

Gujar N, Yoo SS, Hu P, Walker MP (2011) Sleep deprivation amplifies reactivity of brain reward networks, biasing the appraisal of positive emotional experiences. J Neurosci 31:4466-4474. CrossRef Medline

Hanlon EC, Andrzejewski ME, Harder BK, Kelley AE, Benca RM (2005) The effect of REM sleep deprivation on motivation for food reward. Behav Brain Res 163:58-69. CrossRef Medline

Hanlon EC, Benca RM, Baldo BA, Kelley AE (2010) REM sleep deprivation produces a motivational deficit for food reward that is reversed by intraaccumbens amphetamine in rats. Brain Res Bull 83:245-254. CrossRef Medline

Hare TA, Camerer CF, Rangel A (2009) Self-control in decision-making involves modulation of the vmPFC valuation system. Science 324: 646-648. CrossRef Medline

Harvey J, Lacey MG (1996) Endogenous and exogenous dopamine depress EPSCs in rat nucleus accumbens in vitro via D1 receptors activation. J Physiol 492:143-154. CrossRef Medline

Harvey J, Lacey MG (1997) A postsynaptic interaction between dopamine D1 and NMDA receptors promotes presynaptic inhibition in the rat nucleus accumbens via adenosine release. J Neurosci 17:5271-5280. Medline 
Hemmeter UM, Hemmeter-Spernal J, Krieg JC (2010) Sleep deprivation in depression. Exp Rev Neurother 10:1101-1115. CrossRef

Hines DJ, Schmitt LI, Hines RM, Moss SJ, Haydon PG (2013) Antidepressant effects of sleep deprivation require astrocyte-dependent adenosine mediated signaling. Trans Psychiatry 3:e212. CrossRef

Huang YH, Lin Y, Mu P, Lee BR, Brown TE, Wayman G, Marie H, Liu W, Yan Z, Sorg BA, Schlüter OM, Zukin RS, Dong Y (2009) In vivo cocaine experience generates silent synapses. Neuron 63:40-47. CrossRef Medline

Huang YH, Ishikawa M, Lee BR, Nakanishi N, Schlüter OM, Dong Y (2011) Searching for presynaptic NMDA receptors in the nucleus accumbens. J Neurosci 31:18453-18463. CrossRef Medline

Huston JP, Haas HL, Boix F, Pfister M, Decking U, Schrader J, Schwarting RK (1996) Extracellular adenosine levels in neostriatum and hippocampus during rest and activity periods of rats. Neuroscience 73: 99-107. CrossRef Medline

Jentsch JD, Taylor JR (1999) Impulsivity resulting from frontostriatal dysfunction in drug abuse: implications for the control of behavior by reward-related stimuli. Psychopharmacology 146:373-390. CrossRef Medline

Kakihana R, Moore JA (1976) Circadian rhythm of corticosterone in mice: the effect of chronic consumption of alcohol. Psychopharmacologia 46: 301-305. CrossRef Medline

Kalivas PW (2009) The glutamate homeostasis hypothesis of addiction. Nat Rev Neurosci 10:561-572. CrossRef Medline

Kalivas PW, Volkow ND (2005) The neural basis of addiction: a pathology of motivation and choice. Am J Psychiatry 162:1403-1413. CrossRef Medline

Kelley AE (2004) Ventral striatal control of appetitive motivation: role in ingestive behavior and reward-related learning. Neurosci Biobehav Rev 27:765-776. CrossRef Medline

Kelley AE, Swanson CJ (1997) Feeding induced by blockade of AMPA and kainate receptors within the ventral striatum: a microinfusion mapping study. Behav Brain Res 89:107-113. CrossRef Medline

Killgore WD, Balkin TJ, Wesensten NJ (2006) Impaired decision making following $49 \mathrm{~h}$ of sleep deprivation. J Sleep Res 15:7-13. Medline

Koban M, Le WW, Hoffman GE (2006) Changes in hypothalamic corticotropin-releasing hormone, neuropeptide $\mathrm{Y}$, and proopiomelanocortin gene expression during chronic rapid eye movement sleep deprivation of rats. Endocrinology 147:421-431. CrossRef Medline

Kopp C, Longordo F, Nicholson JR, Lüthi A (2006) Insufficient sleep reversibly alters bidirectional synaptic plasticity and NMDA receptor function. J Neurosci 26:12456-12465. CrossRef Medline

Krueger JM, Obál F (1993) A neuronal group theory of sleep function. J Sleep Res 2:63-69. CrossRef Medline

Kushida CA, Bergmann BM, Rechtschaffen A (1989) Sleep deprivation in the rat: IV. Paradoxical sleep deprivation. Sleep 12:22-30. Medline

LaLumiere RT, Smith KC, Kalivas PW (2012) Neural circuit competition in cocaine-seeking: roles of the infralimbic cortex and nucleus accumbens shell. Eur J Neurosci 35:614-622. CrossRef Medline

Lobo MK, Nestler EJ (2011) The striatal balancing act in drug addiction: distinct roles of direct and indirect pathway medium spiny neurons. Front Neuroanat 5:41. Medline

Lobo MK, Covington HE 3rd, Chaudhury D, Friedman AK, Sun H, DamezWerno D, Dietz DM, Zaman S, Koo JW, Kennedy PJ, Mouzon E, Mogri M, Neve RL, Deisseroth K, Han MH, Nestler EJ (2010) Cell type-specific loss of BDNF signaling mimics optogenetic control of cocaine reward. Science 330:385-390. CrossRef Medline

Ma YY, Lee BR, Wang X, Guo C, Liu L, Cui R, Lan Y, Balcita-Pedicino JJ, Wolf ME, Sesack SR, Shaham Y, Schlüter OM, Huang YH, Dong Y (2014) Bidirectional modulation of incubation of cocaine craving by silent synapse-based remodeling of prefrontal cortex to accumbens projections. Neuron 83:1453-1467. CrossRef Medline

MacAskill AF, Little JP, Cassel JM, Carter AG (2012) Subcellular connectivity underlies pathway-specific signaling in the nucleus accumbens. Nat Neurosci 15:1624-1626. CrossRef Medline

Maldonado-Irizarry CS, Swanson CJ, Kelley AE (1995) Glutamate receptors in the nucleus accumbens shell control feeding behavior via the lateral hypothalamus. J Neurosci 15:6779-6788. Medline

Malisch JL, Breuner CW, Gomes FR, Chappell MA, Garland T, Jr (2008) Circadian pattern of total and free corticosterone concentrations, corticosteroid-binding globulin, and physical activity in mice selectively bred for high voluntary wheel-running behavior. Gen Com Endocrinol 156:210-217. CrossRef

Marshall L, Born J (2007) The contribution of sleep to hippocampusdependent memory consolidation. Trends Cogn Sci 11:442-450. CrossRef Medline

Mayberg HS, Lozano AM, Voon V, McNeely HE, Seminowicz D, Hamani C, Schwalb JM, Kennedy SH (2005) Deep brain stimulation for treatmentresistant depression. Neuron 45:651-660. CrossRef Medline

McFarland K, Lapish CC, Kalivas PW (2003) Prefrontal glutamate release into the core of the nucleus accumbens mediates cocaine-induced reinstatement of drug-seeking behavior. J Neurosci 23:3531-3537. Medline

McKenna BS, Dickinson DL, Orff HJ, Drummond SP (2007) The effects of one night of sleep deprivation on known-risk and ambiguous-risk decisions. J Sleep Res 16:245-252. CrossRef Medline

Meyer AC, Neher E, Schneggenburger R (2001) Estimation of quantal size and number of functional active zones at the calyx of Held synapse by nonstationary EPSC variance analysis. J Neurosci 21:7889-7900. Medline

Mogenson GJ, Jones DL, Yim CY (1980) From motivation to action: functional interface between the limbic system and the motor system. Prog Neurobiol 14:69-97. CrossRef Medline

Murphy ER, Dalley JW, Robbins TW (2005) Local glutamate receptor antagonism in the rat prefrontal cortex disrupts response inhibition in a visuospatial attentional task. Psychopharmacology 179:99-107. CrossRef Medline

Muzur A, Pace-Schott EF, Hobson JA (2002) The prefrontal cortex in sleep. Trends Cogn Sci 6:475-481. CrossRef Medline

Nestler EJ, Carlezon WA Jr (2006) The mesolimbic dopamine reward circuit in depression. Biol Psychiatry 59:1151-1159. CrossRef Medline

Nicola SM, Malenka RC (1998) Modulation of synaptic transmission by dopamine and norepinephrine in ventral but not dorsal striatum. J Neurophysiol 79:1768-1776. Medline

Palchykova S, Winsky-Sommerer R, Meerlo P, Dürr R, Tobler I (2006) Sleep deprivation impairs object recognition in mice. Neurobiol Learn Mem 85:263-271. CrossRef Medline

Pennartz CM, Dolleman-Van der Weel MJ, Kitai ST, Lopes da Silva FH (1992) Presynaptic dopamine D1 receptors attenuate excitatory and inhibitory limbic inputs to the shell region of the rat nucleus accumbens studied in vitro. J Neurophysiol 67:1325-1334. Medline

Peters J, LaLumiere RT, Kalivas PW (2008) Infralimbic prefrontal cortex is responsible for inhibiting cocaine seeking in extinguished rats. J Neurosci 28:6046-6053. CrossRef Medline

Phillipson OT, Griffiths AC (1985) The topographic order of inputs to nucleus accumbens in the rat. Neuroscience 16:275-296. CrossRef Medline

Pilcher JJ, Huffcutt AI (1996) Effects of sleep deprivation on performance: a meta-analysis. Sleep 19:318-326. Medline

Porkka-Heiskanen T, Strecker RE, McCarley RW (2000) Brain sitespecificity of extracellular adenosine concentration changes during sleep deprivation and spontaneous sleep: an in vivo microdialysis study. Neuroscience 99:507-517. CrossRef Medline

Puhl MD, Fang J, Grigson PS (2009) Acute sleep deprivation increases the rate and efficiency of cocaine self-administration, but not the perceived value of cocaine reward in rats. Pharmacol Biochem Behav 94:262-270. CrossRef Medline

Puhl MD, Boisvert M, Guan Z, Fang J, Grigson PS (2013) A novel model of chronic sleep restriction reveals an increase in the perceived incentive reward value of cocaine in high drug-taking rats. Pharmacol Biochem Behav 109:8-15. CrossRef Medline

Qi J, Zhang S, Wang HL, Barker DJ, Miranda-Barrientos J, Morales M (2016) VTA glutamatergic inputs to nucleus accumbens drive aversion by acting on GABAergic interneurons. Nat Neurosci 19:725-733.

Quastel DM (1997) The binomial model in fluctuation analysis of quantal neurotransmitter release. Biophys J 72:728-753. CrossRef Medline

Riga D, Matos MR, Glas A, Smit AB, Spijker S, Van den Oever MC (2014) Optogenetic dissection of medial prefrontal cortex circuitry. Front Syst Neurosci 8:230. Medline

Robbins TW, Everitt BJ (1996) Neurobehavioural mechanisms of reward and motivation. Curr Opin Neurobiol 6:228-236. CrossRef Medline

Salgado S, Kaplitt MG (2015) The nucleus accumbens: a comprehensive review. Stereotact Funct Neurosurg 93:75-93. CrossRef Medline

Saviane C, Silver RA (2007) Estimation of quantal parameters with multiple-probability fluctuation analysis. Methods Mol Biol 403:303317. CrossRef Medline 
Scheuss V, Neher E (2001) Estimating synaptic parameters from mean, variance, and covariance in trains of synaptic responses. Biophys J 81:19701989. CrossRef Medline

Scheuss V, Schneggenburger R, Neher E (2002) Separation of presynaptic and postsynaptic contributions to depression by covariance analysis of successive EPSCs at the calyx of Held synapse. J Neurosci 22:728-739. Medline

Sesack SR, Grace AA (2010) Cortico-basal ganglia reward network: microcircuitry. Neuropsychopharmacology 35:27-47. CrossRef Medline

Shen Y, Cao X, Tan T, Shan C, Wang Y, Pan J, He H, Yuan TF (2016) 10-Hz repetitive transcranial magnetic stimulation of the left dorsolateral prefrontal cortex reduces heroin cue craving in long-term addicts. Biol Psychiatry Published online ahead of print February 12, 2016. pii: S00063223(16)00093-7. doi:10.1016/j.biopsych.2016.02.006.

Shuen JA, Chen M, Gloss B, Calakos N (2008) Drd1a-tdTomato BAC transgenic mice for simultaneous visualization of medium spiny neurons in the direct and indirect pathways of the basal ganglia. J Neurosci 28:26812685.

Silver RA (2003) Estimation of nonuniform quantal parameters with multiple-probability fluctuation analysis: theory, application and limitations. J Neurosci Methods 130:127-141. CrossRef Medline

Spanagel R, Weiss F (1999) The dopamine hypothesis of reward: past and current status. Trends Neurosci 22:521-527. CrossRef Medline

Steiner SS, Ellman SJ (1972) Relation between REM sleep and intracranial self-stimulation. Science 177:1122-1124. CrossRef Medline

Stratford TR, Kelley AE (1997) GABA in the nucleus accumbens shell participates in the central regulation of feeding behavior. J Neurosci 17: 4434-4440. Medline

Stratford TR, Swanson CJ, Kelley A (1998) Specific changes in food intake elicited by blockade or activation of glutamate receptors in the nucleus accumbens shell. Behav Brain Res 93:43-50. CrossRef Medline

Suchecki D, Lobo LL, Hipólide DC, Tufik S (1998) Increased ACTH and corticosterone secretion induced by different methods of paradoxical sleep deprivation. J Sleep Res 7:276-281. CrossRef Medline

Suska A, Lee BR, Huang YH, Dong Y, Schlüter OM (2013) Selective presynaptic enhancement of the prefrontal cortex to nucleus accumbens pathway by cocaine. Proc Natl Acad Sci U S A 110:713-718. CrossRef Medline

Telzer EH, Fuligni AJ, Lieberman MD, Galván A (2013) The effects of poor quality sleep on brain function and risk taking in adolescence. Neuroimage 71:275-283. CrossRef Medline
Terraneo A, Leggio L, Saladini M, Ermani M, Bonci A, Gallimberti L (2016) Transcranial magnetic stimulation of dorsolateral prefrontal cortex reduces cocaine use: a pilot study. Eur Neuropsychopharmacol 26:37-44. CrossRef Medline

Tritsch NX, Sabatini BL (2012) Dopaminergic modulation of synaptic transmission in cortex and striatum. Neuron 76:33-50. CrossRef Medline

Venkatraman V, Chuah YM, Huettel SA, Chee MW (2007) Sleep deprivation elevates expectation of gains and attenuates response to losses following risky decisions. Sleep 30:603-609. Medline

Venkatraman V, Huettel SA, Chuah LY, Payne JW, Chee MW (2011) Sleep deprivation biases the neural mechanisms underlying economic preferences. J Neurosci 31:3712-3718. CrossRef Medline

Volkow ND, Tomasi D, Wang GJ, Telang F, Fowler JS, Logan J, Benveniste H, Kim R, Thanos PK, Ferré S (2012) Evidence that sleep deprivation downregulates dopamine $\mathrm{D} 2 \mathrm{R}$ in ventral striatum in the human brain. J Neurosci 32:6711-6717. CrossRef Medline

Wang W, Dever D, Lowe J, Storey GP, Bhansali A, Eck EK, Nitulescu I, Weimer J, Bamford NS (2012) Regulation of prefrontal excitatory neurotransmission by dopamine in the nucleus accumbens core. J Physiol 590:3743-3769. CrossRef Medline

Winters BD, Huang YH, Dong Y, Krueger JM (2011) Sleep loss alters synaptic and intrinsic neuronal properties in mouse prefrontal cortex. Brain Res 1420:1-7. CrossRef Medline

Wu J, Buchsbaum MS, Gillin JC, Tang C, Cadwell S, Wiegand M, Najafi A, Klein E, Hazen K, Bunney WE Jr, Fallon JH, Keator D (1999) Prediction of antidepressant effects of sleep deprivation by metabolic rates in the ventral anterior cingulate and medial prefrontal cortex. Am J Psychiatry 156:1149-1158. Medline

Yawata S, Yamaguchi T, Danjo T, Hikida T, Nakanishi S (2012) Pathwayspecific control of reward learning and its flexibility via selective dopamine receptors in the nucleus accumbens. Proc Natl Acad Sci U S A 109: 12764-12769. CrossRef Medline

Yizhar O, Fenno LE, Prigge M, Schneider F, Davidson TJ, O'Shea DJ, Sohal VS, Goshen I, Finkelstein J, Paz JT, Stehfest K, Fudim R, Ramakrishnan C, Huguenard JR, Hegemann P, Deisseroth K (2011) Neocortical excitation/inhibition balance in information processing and social dysfunction. Nature 477:171-178. CrossRef Medline

Yoo SS, Gujar N, Hu P, Jolesz FA, Walker MP (2007) The human emotional brain without sleep-a prefrontal amygdala disconnect. Curr Biol 17: R877-R878. CrossRef Medline 